\title{
Unmet therapeutic, educational and scientific needs in parathyroid disorders: Consensus Statement from the first European Society of Endocrinology Workshop (PARAT)
}

\author{
Jens Bollerslev 1,2, Camilla Schalin-Jäntti ${ }^{3}$, Lars Rejnmark', Heide Siggelkow ${ }^{5}$, Hans Morreau ${ }^{6}$, Rajesh Thakker7, \\ Antonio Sitges-Serra ${ }^{8}$, Filomena Cetani ${ }^{9}$ and Claudio Marcocci ${ }^{9}$ on behalf of the PARAT Workshop Group ${ }^{\dagger}$
}

${ }^{1}$ Section of Specialized Endocrinology, Oslo University Hospital, ${ }^{2}$ Faculty of Medicine, University of Oslo, Oslo, Norway, ${ }^{3}$ Division of Endocrinology, Abdominal Center, Helsinki University Hospital and University of Helsinki, Helsinki, Finland, ${ }^{4}$ Department of Endocrinology and Internal Medicine, Aarhus University Hospital, Aarhus, Denmark, ${ }^{5}$ Endokrinologikum Göttingen, Georg-August-University Göttingen, Göttingen, Germany, ${ }^{6}$ Pathology, Leiden University Medical Center, Leiden, Netherlands, ${ }^{7}$ Academic Endocrine Unit, Radcliffe Department of Medicine, University of Oxford, Churchill Hospital, Oxford, UK, ${ }^{8}$ Endocrine Surgery Unit, Hospital del Mar, Universitat Autònoma de Barcelona, Barcelona, Spain, and ${ }^{9}$ Department of Clinical and Experimental Medicine, University of Pisa, Pisa, Italy

Correspondence should be addressed to J Bollerslev Email jens.bollerslev@medisin. uio.no

\begin{abstract}
PARAT, a new European Society of Endocrinology program, aims to identify unmet scientific and educational needs of parathyroid disorders, such as primary hyperparathyroidism (PHPT), including parathyroid cancer (PC), and hypoparathyroidism (HypoPT). The discussions and consensus statements from the first PARAT workshop (September 2018) are reviewed. PHPT has a high prevalence in Western communities, yet evidence is sparse concerning the natural history and whether morbidity and long-term outcomes are related to hypercalcemia or plasma PTH concentrations or both. Cardiovascular mortality and prevalence of low energy fractures are increased, whereas quality of life is decreased, although their reversibility by treatment of PHPT has not been convincingly demonstrated. PC is a rare cause of PHPT, with increasing incidence, and international collaborative studies are required to advance knowledge of the genetic mechanisms, biomarkers for disease activity and optimal treatments. For example, $20 \%$ of PCs demonstrate high mutational burden, and identifying targetable DNA variations, gene amplifications and gene fusions may facilitate personalized care, such as different forms of immunotherapy or targeted therapy. HypoPT, a designated orphan disease, is associated with a high risk of symptoms and complications. Most cases are secondary to neck surgery. However, there is a need to better understand the relation between disease biomarkers and intellectual function and to establish the role of PTH in target tissues, as these may facilitate the appropriate use of PTH substitution therapy. Management of parathyroid disorders is challenging, and PARAT has highlighted the need for international transdisciplinary scientific and educational studies in advancing in this field.
\end{abstract}

\section{Introduction}

Disorders in the parathyroid glands spans a huge variety of clinical important diseases, some with a very high prevalence as in primary hyperparathyroidism (PHPT) among postmenopausal women $(1,2,3,4)$, some orphan like chronic hypoparathyroidism in adults (HypoPT) $(5,6)$, with increasing awareness due to new treatment 
algorithms (7). Parathyroid carcinomas (PC) are extremely rare, but might potentially be underdiagnosed $(8,9$, 10). By far most of parathyroid diseases are sporadic as most cases of PHPT, some are part of well-known genetic conditions. As such, PHPT is linked to the multiple endocrine neoplasia (MEN) syndromes (11), and familial hypocalciuric hypercalcemia (FHH) ) is a well-described, rare autosomal dominant inherited condition most often due to a loss-of-function mutation in the calcium sensor and partner proteins $(12,13)$. Thus, parathyroid disorders are heterogeneous conditions with the organs (the glands) in common and with clinical awareness and interest often reflecting new developments in diagnostic procedures or treatment possibilities.

The European Society of Endocrinology (ESE) recently established a new program focusing on parathyroid disorders - the PARAT program - aiming to identify unmet scientific and educational needs in parathyroid diseases. The first workshop in Santpoort, The Netherlands in September 2018 invited European Top-experts within the three main topics, PC, PHPT and HypoPT, based on State of the Art Presentations by international experts followed by break-out sessions to identify the needs in each area and a further discussion in plenum on prioritizing the way forward in a 2- to 4-year perspective. The aim of this review is to summarize and discuss the recent achievements on these three defined topics.

\section{Parathyroid carcinoma}

PC is one of the most rare known malignancies and accounts for less than 1\% of PHPT. Reports from the United States, Australia and Finland indicate increasing incidences $(8,9,10)$. Preoperatively, PC cannot be distinguished from benign causes of PHPT, as no diseasespecific markers are available. PC should be suspected in patients with severe PTH-dependent hypercalcemia or its complications (14), but may be overlooked because it is so rare. PC is rather aggressive with a high recurrence rate in more than $50 \%$ of the cases and the 5-year survival rate in patients with metastatic disease is less than $50 \%(15,16$, 17). Patients suspected to have PC should have primary radical en bloc surgery, performed by an experienced surgeon (18), as this is the only treatment that can ensure cure. Diagnosis is confirmed by histopathology, which also is demanding. Therefore, some patients are correctly diagnosed only because of persistent disease after surgery or later recurrent/metastatic disease. Histopathology should always be performed by an expert parathyroid pathologist in a standardized fashion. A main challenge is to distinguish PC from an atypical parathyroid adenoma. PC is usually sporadic, but may be part of familial syndromes such as hyperparathyroidism-jaw tumour syndrome (HPT-JT), isolated familial hyperparathyroidism (FIHP) and, rarely, MEN1 or MEN2A $(18,19)$. CDC73 germline mutations cause HPT-JT and, in $20-40 \%$ of the cases sporadic PC. In contrast to parathyroid adenomas, a majority of PCs are characterized by somatic $C D C 73$ mutations $(20,21)$. CDC73 is a tumour suppressor gene that encodes parafibromin. In PC, vascular tumour invasion and loss of parafibromin expression associate with more aggressive behavior and impaired patient survival $(10,18,22)$. Genetic testing should be offered to all patients with PC and when mutation positive, also first-degree relatives should be screened. For patients with inoperable disease, treatment options are limited. Treatment of hypercalcemia is crucial; however, no evidence-based disease-specific treatment exist. Given the rarity of PC, a collaborative approach is needed in order to develop novel diagnostic markers and targeted drugs, and hopefully improve outcomes.

\section{Preoperative diagnosis of parathyroid carcinoma}

The diagnosis of PC is challenging due to the lack of reliable clinical diagnostic criteria and is in the majority of cases made postoperatively by histological examination. Local invasion of surrounding structures (trachea, inferior laryngeal nerve, strap muscles) and the occurrence of distant or lymph node metastases are the only unequivocal criteria of malignancy. The latter, however, usually develop late during follow-up. Patients who present with a palpable mass, a serum calcium level higher than $3.5 \mathrm{mmol} / \mathrm{L}$ and markedly elevated PTH levels, severe renal and/or bone disease involvement and/or laryngeal nerve palsy should be suspected of harboring PC (18). Very rarely however, PC is nonfunctioning, that is patients have normal levels of plasma calcium and PTH (23).

Currently, no standard imaging studies are able to distinguish PC from a benign parathyroid lesion. Nonetheless, some ultrasound (US) features may raise the suspicion for PC, namely a large (i.e. $>3 \mathrm{~cm}$ large) lobulated hypoechoic/heterogeneous parathyroid gland, with irregular borders, thick capsule, suspicious vascularity and calcifications (24) (Fig. 1). However, these features may also be seen in benign tumors (25). Conversely, Hara et al. observed that the depth/width ratio of the lesion $>1$ suggest a PC, while $<1$ a benign tumor (25). Occasionally, 


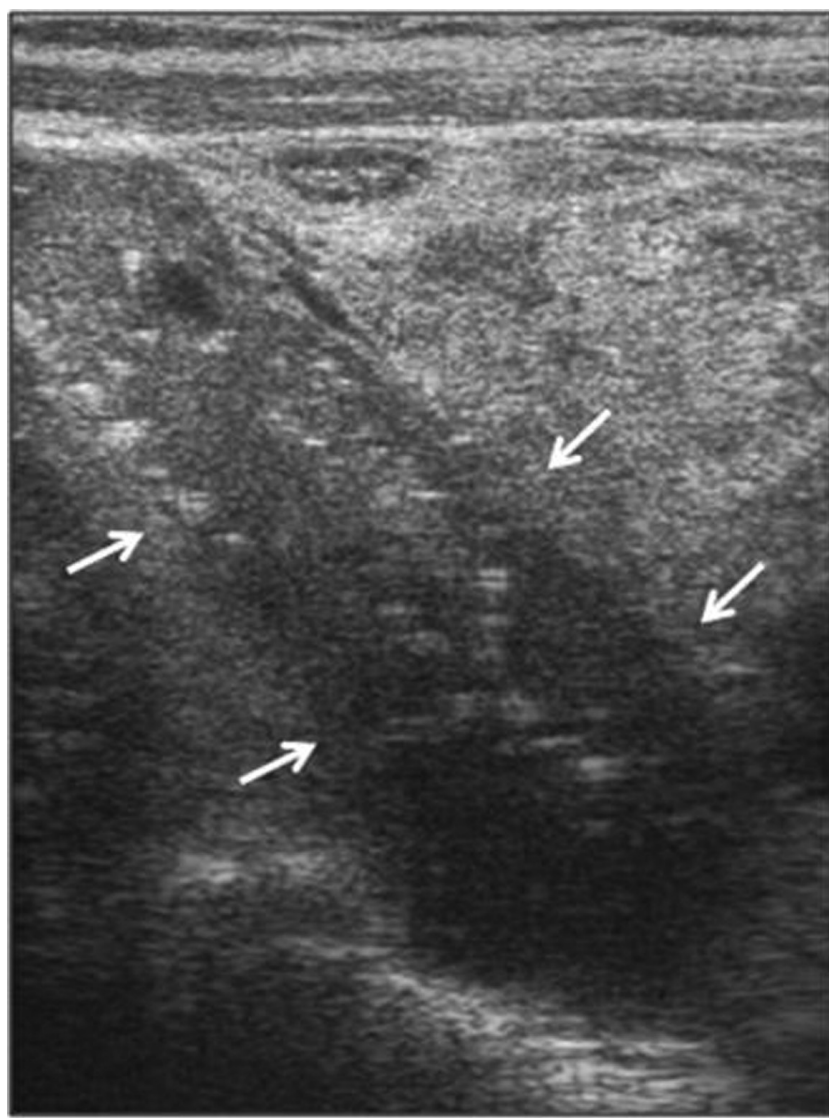

\section{Figure 1}

Ultrasound image of a parathyroid carcinoma. The tumor (arrows), located at the upper pole of the thyroid, shows a heterogeneous pattern, irregular shape and halo sign (longitudinal view) (from Cetani et al. JEI 2016, with permission (18)).

the infiltration into surrounding tissues and cervical lymph node enlargement can be identified (or suspected). 99mTc-sestamibi (MIBI) scan is routinely used for imaging abnormal/ectopic parathyroid lesion but cannot predict malignancy. When there is a strong suspicion for PC higher resolution studies can be useful, namely contrast computed tomography (CT), including 4-dimensional computed tomography (4DCT), magnetic resonance imaging (MRI) with gadolinium or positron emission tomography (PET)/CT with 2-[fluorine-18]-fluoro-2deoxyD-glucose (18F-FDG) (26). CT and MRI can accurately locate the lesion and its relationship with or invasion into adjacent tissues. Both are commonly used when planning en bloc resection of the lesion and surrounding structures. The sensitivity of a single preoperative imaging (US, CT or MIBI) has been reported to be $\sim 80 \%$ but this increases up to $95 \%$ when the three procedures are used together (26).
Thus, in a given patient with suspicion for PC combined preoperative imaging studies are recommended. The role of FDG-PET is still debated; of note, the lesions of osteitis fibrosa cystica, which can be present in patients with PC, are hypermetabolic and positive at FDG-PET and, therefore, could be misdiagnosed as bone metastasis (27). Preoperative fine-needle parathyroid biopsy is not recommended because it cannot distinguish a benign from a malignant lesion and has a risk of tumoral rupture and seeding (28).

\section{Pathogenesis and histopathology}

\section{Pathogenesis}

PC can arise in the context of the CDC73 related disorder (or HPT-JT syndrome and anecdotally in the context of MEN1 and MEN2A syndromes). Sporadic inactivation of CDC73 and other genetic factors are driving parathyroid cancers, but there are no data why these DNA variations would occur in these relatively oligo-dividing parathyroid cells, with a relatively low chance of replication errors and less environmental influences (including lifestyle) than seen in other tumor types (29). However, a history of radiation exposure has been reported in PC (30). Proliferation of parathyroid cells due to renal failure with secondary hyperparathyroidism might occasionally drive parathyroid tumorigenesis towards malignancy (31). An alternative explanation for which there is no formal proof is that in metabolically hyperactive cells increased reactive oxygen species might lead to subsequent DNA damage targeting crucial pathways in parathyroid homeostasis. As also postulated by Tomasetti and Vogelstein for cancers in general, possibly bad luck is another valid explanation for PC tumorigenesis (29).

\section{Histopathology}

The correct histopathological diagnosis of malignancy (WHO Classification of Tumours of Endocrine Organs, 2017) is primarily based on two strict criteria, that is, ingrowth of tumor cells beyond the preexistent parathyroid capsule into surrounding tissues and the presence of lymphangio-invasiveness. The presence of atypical mitotic figures and fibrous septa may be helpful as they are often associated with malignancy. An example of PC is given in Fig. 2. Other criteria like nuclear atypia and the lack of uniformity of the cells are being more circumstantial. Additional immunohistochemical staining may help to support the diagnosis and the ones that are 


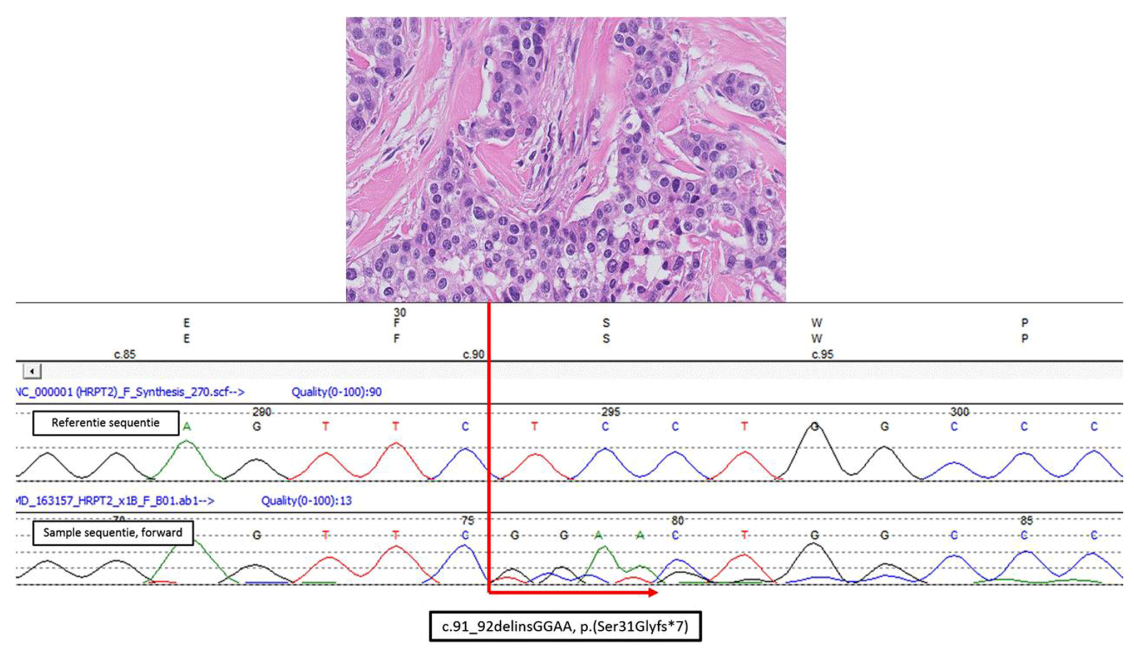

\section{Figure 2}

Histopathology: Parathyroid carcinoma in the context of CDC73-related disorder. Concerns index patient III.2 of family G described by van der Tuin et al. (Supplementary Fig. 1 and Supplementary Table 1 in the reference (38)). This male patient was diagnosed with PC at the age 45 years after he presented with primary hyperparathyroidism and a right-sided mass in the neck of $6 \mathrm{~cm}$ with lymph node metastases. The patient eventually died of this disease. Germ line CDC73 (HRPT2) analysis showed a large deletion of the q-arm of chromosome 1 including the complete CDC73 gene. In the upper part of the figure, a hematoxylin and eosin stained histological slide is presented. The tumour showed pleiomorphic parathyroid hormone positive staining cells with anisokaryosis and prominent nucleoli. Broad fibrous bands were between tumour cell islands. Occasionally mitoses were observed. The Ki-67 index was focally around 5\%. Lymph angio-invasiveness outside the tumour mass was seen. Parafibromin immunohistochemistry showed vague positive and focal complete lack of nuclear staining of tumour cell in comparison with internal reference cells. There was enhanced cytoplasmic staining of tumour cells. In the lower part of the figure somatic CDC73 (HRPT2) Sanger DNAsequencing results are depicted showing a forward reference sequence above the tumour sequence. This region was not well covered in a targeted CDC73 containing gene panel for next-generation sequencing that was also analysed. In the tumour as a second hit on the wild type allele a pathogenic CDC73 exon 1: c.91_92delinsGGAA, p.(Ser31Glyfs*7) gene variant was identified.

used currently are Ki67, Galectin 3, protein gene product 9.5 (PGP9.5) and parafibromin (encoded by CDC73) (32). Furthermore, loss of parafibromin expression and the finding of inactivating CDC73 DNA variants can be found in aggressively behaving parathyroid cancers $(33,34)$, and as such provide prognostic information.

At this moment, there are no well-established tissue biomarkers that can delineate parathyroid carcinoma (unequivocal carcinoma) from atypical adenomas (or equivocal carcinoma). For example, there is no evidence that recently described limited gene panels for PC (as outlined in the section titled 'Germline mutation testing') or larger commercial gene panels can be helpful to answer such diagnostic questions. Probably only finding CDC73 pathogenic variants would point to a more aggressive potential although only in cases with histological confirmation. Finding MEN1 variants would shift the odds to a more benign potential. Other biomarkers, such as microRNA profiles might be thought of.

\section{Germline mutation testing}

Testing for germline mutation of the CDC73 gene is strongly recommended in patients with apparently sporadic PC. The mutation detection yield ranges from 6 to $38 \%$ according to the different studies $(10,21,33,35$, $36,37,38)$. The sample size, the selection bias and, not less important, the challenging of the histopathological diagnosis, could account for these differences. However, the latter is of utmost importance because it determines the prognosis of the patients. The majority of these mutations is widespread throughout the coding region, but most are located in exons 1, 2 and 7 (10, 21, 33, 35, $36,37,38)$. Gross deletions within the gene have been identified in a few cases of patient with PC $(37,38,39)$. Therefore, in CDC73-negative cases for point/small mutations, the research of CDC73 gross deletions should be considered.

Germline mutations in additional genes including PRUNE2, CCD1, ADCK1 and genes of PI3K/AKT/mTOR 
pathways have been detected in patients with PC (40, 41). Therefore, gene panel testing using next-generation sequencing should be considered because it would improve the genetic analysis.

In clinical practice, the genetic testing for germline mutations is helpful in the index case and, if positive, first-degree relatives of all patients with PC in order to

(i) identify the germline mutation in a given patient with PC;

(ii) identify asymptomatic family members carrying the mutation and thus requiring a clinical evaluation for early detection of the tumor and appropriate treatment;

(iii) relieve the anxiety of developing the disease family members who do not carry the mutation;

(iv) start the screening for HPT-JT-related tumors in the index case and healthy carriers. Indeed, patients with CDC73-related disorders might develop ossifying fibromas of the maxilla and/or mandible and uterine tumors and renal lesions.

\section{Surgery of parathyroid carcinoma}

Successful surgery depends on preoperative suspicion of PC and intraoperative recognition of malignant features, such as size (often $>3 \mathrm{~cm}$ ), firmness, grayish-white color and adherence/invasion to surrounding tissues. Local excision is not acceptable, the only way of ensuring cure is complete removal of the tumor while avoiding capsule rupture and including all surrounding tissues involved (en bloc resection) (22). Achieving microscopically disease-free margins improves disease-free survival (42). Prognosis is influenced by surgeon performance (43). If PC is suspected, surgery should thus be performed by an expert parathyroid surgeon in a large-volume center. If the patient has not undergone primary en bloc resection and histopathological confirmation of PC comes as a surprise, timely further expert parathyroid surgery must be considered. Surgery is first-line treatment also for recurrent disease and, in selected cases repeated operations in combination with other systemic treatments may improve the prognosis (44).

\section{Systemic treatments}

Most patients with inoperable PC ultimately succumb to severe hypercalcemia and kidney failure rather than tumour burden. The management of acute severe hypercalcemia includes intravenous saline infusion to restore fluid volume and increase urinary calcium excretion, and occasionally loop diuretics to enhance the calciuresis $(16,18,45)$. However, such measures are of temporary success only, and other approaches (e.g. drugs such as cinacalcet) are required for longer-term success. Cinacalcet, a calcimimetic binding to the calcium-sensing receptor and thereby decreases PTH secretion, is a potent oral calcium-lowering agent. The starting dose is $30 \mathrm{mg}$ twice daily, with dose adjustments every 2 weeks until calcium concentrations are acceptable (17). Nausea is a common side effect that may prevent the usage of higher doses. Cinacalcet can be combined with zoledronic acid (44), the most potent known bisphopshonate ( $4 \mathrm{mg}$ i.v every 3-4 weeks) or, with denosumab, a monoclonal antibody that binds to RANKL (120 mg s.c monthly), especially in refractory cases and patients with impaired kidney function $(46,47)$. There are however, no evidence-based specific treatments. Anecdotal positive responses to adjuvant radiotherapy (10, 48, 49, 50), PTH immunotherapy $(51,52)$ and alkylating agents as iv dacarbazine (53) and oral temozolomide have been reported (44).

\section{Future networking, biobanking, future joint efforts for a deeper understanding of pathogenesis, to enable tailored treatments}

It is of paramount importance to refer patients with suspicion of PC to tertiary care centers with skilled endocrine surgeons who are familiar with the treatment of this rare disease. It would be very desirable to set-up European prospective registries and biobanks to collect large number of patients with PC and bio-specimens (tissues, blood, serum, urine, etc). Such a project would ensure an adequate sample size to improve our understanding on not yet clear clinical preoperative, surgical and histological findings. One of the main goals would be to define preoperative biomarkers to differentiate between malignant lesions and the much more common benign counterpart, and subsequently a better understanding of the pathogenesis of PC. This would lead to better planning the initial surgical procedure as this greatly influences the prognosis of patients with PC and their management.

Extensive epidemiological data on the occurrence of PC have so far not been compiled from all countries in Europe and results on treatment outcomes have not been evaluated. Treatment options for recurrent PC are so far limited. Being a rare disease, the treatment of recurrent PC can benefit from the developments in personalized cancer care. These developments encompass the elucidation 
of relatively rare but targetable DNA variations, gene amplifications and gene fusions across many cancer types $(54,55)$. For example, DNA alterations of the PIK3CAPTEN-mTOR-AKT pathway, gene amplifications (HER2, FGFR3 etc.) or gene fusions (involving $A L K, R O S, R E T$, $N T R K)$ are seen in different cancer types, although with different frequencies. Indeed, recent studies reported potentially targetable ROS1, TSC1, AKT1, MTOR, PTEN, PIK3CA, NF1, KDR, ERBB1, NTRK1, IDH1 and FGFR3 DNA variants in PC in the presence or absence of CDC73 mutations, with rationally matched targeted agents (41, 56, 57). Single PC cases showed clinical benefit from tyrosine kinase inhibitors (56). In PC cases with high mutational loads or burdens, the applicability of different forms of immunotherapy (for example anti PD1 immune de-blockade therapy) might be envisioned. Although the median total mutational burden in PC is relatively low (1.7 mutations per megabase (m/Mb), about $20 \%$ demonstrated high mutational burden (>20 m/Mb)) (40, 56). The latter translates into a higher neo-antigen load with a chance that abnormal tumor peptide fragments are presented on the tumor cell surface in the context of HLA and thereby leading to cytotoxic T-cell responses $(58,59)$. Repurposing existing drugs can be thought of as shown by the effectivity of temozolomide in an isolated PC case (44). As stated, there is a relatively high frequent inactivation of $C D C 73$ in PC. The parafibromin protein encoded by CDC73 is part of the PAF1 complex involved in cell cycle regulation. It should be studied whether the latter would impose increased sensitivity to cell cycle inhibitors. Similarly cyclin D1 might be targeted as CCND1 is found to be amplified in PC cases, reviewed recently by Costa-Guda (60). In human cancers with P16 loss (encoded by CDKN2A), cell cycle inhibitors are given (CDK4/6 inhibitors) (61). To bring this field further, PC-specific comprehensive integrative molecular analysis (of the mutome, transcriptome, methylome, miRNAome, etc.) is lacking. So far, isolated relatively small series of PC have been studied by extensive genomic analysis including exome analysis (40, 41, 56, 62, 63). There are no well-characterized cell lines available to facilitate biological research. For this purpose, future networking is of utmost importance to improve research and the treatment possibilities in recurrent PC.

\section{Chronic hypoparathyroidism in adults}

Hypoparathyroidism (HypoPT) is a rare disease with an estimated prevalence of $\sim 30$ patients per 100,000 people
(64). In adults, chronic HypoPT is most often secondary to neck surgery, having a surprisingly high prevalence of 10-24/100.000 inhabitants $(6,64,65)$. From a therapeutic aspect, HypoPT is the last endocrine deficiency syndrome not replaced by the lacking hormone in standard care (7, 66). The indirect standard treatment or an un-physiologic substitution therapy might give challenges affecting quality of life (QoL) for the patients but also potential long-term complications $(6,67,68,69,70,71)$.

\section{The diagnosis of hypoparathyroidism}

HypoPT has been clearly defined in the guidelines on 'Treatment of chronic hypoparathyroidism in adults' by ESE as 'a disease with hypocalcaemia and inappropriately low parathyroid hormone (PTH) levels' (7). A similar definition has been suggested by other expert groups $(66,72)$. Despite this general consensus, it seems that HypoPT is defined in many different ways in the scientific literature. In 2010, Mehanna et al. (73) published a review on papers reporting risk of postoperative hypocalcemia. Based on a systematic literature search, a total of 62 papers were identified. The majority of the papers did not specifically define hypocalcemia and the papers reporting this used ten different definitions. By applying these 10 different definitions to the same cohort of 202 thyroid surgery cases at a single institution, it was found that that the incidence of hypocalcemia varied widely (0-46\%) depending on the definition used. Most recently, another systematic literature review has been published on papers reporting on risk of permanent postsurgical HypoPT between 2010 and 2011 (74). The review identified 89 articles using 20 different definitions and reported an incidence varying from $0.0-20.2 \%$. None of the definitions used were in accordance with the generally accepted definition. Accordingly, there is a need for standardization of the definitions used for reporting hypocalcemia rates. Otherwise, patients are not diagnosed in a proper manner and thereby may not receive appropriate treatment.

\section{HypoPT is a complicated disease}

It has become more and more clear that HypoPT is more than just a matter of supplying calcium and activated vitamin D. HypoPT is a complicated disease with deficiency of two hormones, PTH and 1,25 (OH) 2 Vit D (64) (Fig. 3). In addition to hypocalcemia, HypoPT is associated with other biochemical disturbances, such as hypercalciuria and hyperphosphatemia, as well as an impaired quality of life and an increased risk of co-morbidities, including 


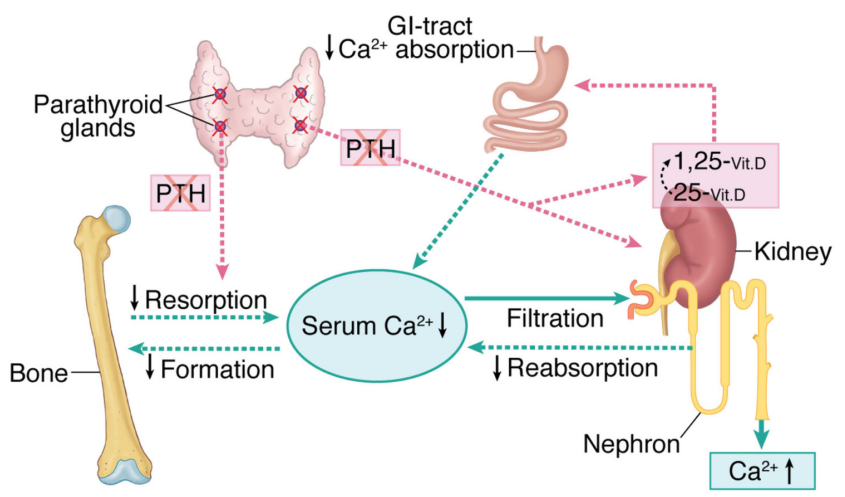

Figure 3

Overall calcium homeostasis in chronic hypoparathyroidism. In chronic hypoparathyroidism in adults, overall calcium metabolism is reflected by the lack of PTH. Bone turnover is markedly decreased as is the net release of calcium from the stores in bone. Levels of active vitamin D (1.25- $\left.(\mathrm{OH})_{2}-\mathrm{Vit} \mathrm{D}\right)$ are low due to lack of the PTH driven 1- $\alpha$-hydroxylase followed by decreased intestinal absorption of calcium. The renal tubular reabsorption of calcium is decreased. Moreover, phosphate levels are high - not illustrated in the figure.

renal stones/impairment, neuropsychiatric diseases and infections.

\section{Renal stones}

Huge variations in the prevalence of renal stones have been reported, varying from 1.9-40\%. As shown in Table 1, the presence of renal stones has been assessed by different methods, which at least in part may explain this variability. Only few studies have compared the risk of renal stones in HypoPT with the general population. A recent cross-sectional study from Italy reported renal calcifications in 30\% of patients with HypoPT, which was eight-fold higher than that in an age- and gendermatched control group (odds ratio (OR) 8.2; 95\% confidence interval (95\% CI) 3.4-19.9) (75). On the contrary, a Danish controlled cohort study reported the risk of renal stones to be 'only' four-fold increased (OR 4.0; 95\% CI, 1.6-9.9), compared to the general population (65). In the Italian study, renal calcifications were assessed by ultrasound examinations and most patients were asymptomatic, whereas hospital discharge codes were used in the Danish study and most patients were symptomatic. Accordingly, HypoPT seems to be associated with a four- and eight-fold increased risk of symptomatic and asymptomatic renal calcifications.

\section{Hypercalciuria}

Idiopathic hypercalciuria occurs with a prevalence of $5-10 \%$ in the general population and is associated with an increased risk of renal stones (76). Due to the lack of PTH, renal calcium excretion is increased in HypoPT (Fig. 3) and a prevalence of hypercalciuria as high as $25-50 \%$ has been reported $(75,77,78)$. Although no good data are available on associations between renal calcium excretion and the risk of renal stones in HypoPT, it seems likely to consider hypercalciuria as a causative factor for the increased risk of renal stones in HypoPT.

In general, it is recommended to aim at serum calcium levels in the low-normal range when treating HypoPT (7). The reason is the well-known association between serum and urinary calcium that is, renal calcium excretion increases with increased serum calcium levels (79). Furthermore, thiazide diuretics have been shown to decrease urinary calcium in HypoPT and may increase serum calcium levels, thereby lowering needs for calcium supplements and activated vitamin D analogues (80). In idiopathic hypercalciuria, thiazides have been shown to reduce the risk of renal stones and it seems likely that thiazides may exert a similar effect in HypoPT (81). However, the precise indication for use of thiazides in HypoPT needs further evaluations.

Table 1 Prevalence of renal calcifications in hypoparathyroidism as reported in studies from different countries.

\begin{tabular}{|c|c|c|}
\hline & Country & No of patients \\
\hline Underbjerg 2013 (64) & Denmark & 688 \\
\hline Arlt 2002 (66) & USA & 25 \\
\hline Rubin 2008 (152) & USA & 33 \\
\hline Hadker 2014 (153) & USA & 374 \\
\hline Meola 2018 (74) & Italy & 82 \\
\hline Lopes 2016 (154) & Brazil & 40 \\
\hline Mitchell 2012 (77) & USA & 54 \\
\hline Winer 2003 (155) & USA & 27 \\
\hline
\end{tabular}

\begin{tabular}{lcc}
\hline Type of examinations & Prevalence of renal calcifications (\%) \\
\cline { 1 - 2 } ICD codes & 1.9 \\
Ultrasound & 8 \\
? & 15 \\
Self-reported & 25 \\
Ultrasound & 30 \\
Ultrasound & 25 \\
Renal imaging & 31 \\
CT scans & 40 \\
\hline
\end{tabular}




\section{Sodium restriction}

Salt restriction has been associated with decreased 24-h renal calcium excretion in subjects with hypercalciuria, as a high sodium intake increases calcium excretion which also may lower serum calcium levels in HypoPT (82). Some patients with HypoPT are prone to develop sudden episodes of hypocalcemia without any obvious explanation. It should be further investigated whether an intermittent high intake of sodium may contribute to fluctuations in serum calcium levels in HypoPT.

\section{Biochemistry and risk of complications}

In a recent study, risk of complications to HypoPT has been associated with the biochemical profile (83). Accordingly, relatively high plasma phosphate levels and/ or a high calcium-phosphate product was associated with an increased mortality as well as an increased risk of renal diseases and infections. Low levels of ionized calcium were associated with an increased risk of cardiovascular diseases and episodes of hypercalcemia were associated with increased mortality and risk of infections, cardiovascularand renal-diseases, beyond kidney calcifications. Whether improving the biochemical control can lower risk of complications of HypoPT needs to be investigated in further prospective studies.

\section{Are our patients well treated?}

A comparison of different treatment forms in HypoPT on biochemical parameters or complications are not available to date. Treatment seems rather to depend on the availability of active vitamin D compounds in different countries. In a Danish study, alfacalcidol was exclusively used (84), in the USA calcitriol (78), in Norway both active compounds were given (6), whereas in Germany in addition to calcitriol and alfacalcidol, the long-acting dihydrotachysterol is available (67). Furthermore, the use of supplemental calcium differs geographically, being highest in the USA (78), whereas higher doses of active vitamin D are used in Europe $(6,67,84,85)$. The European guidelines and international recommendations $(7,66)$ propose an standardized treatment with the aim of reducing symptoms and complications by control of multiple biochemical parameters beyond serum calcium, including serum phosphate, calcium-phosphate product, magnesium and urinary calcium excretion (7). A crosssectional study from Italy indicated that only 34.1\% treated with conventional therapy (calcium and calcitriol) met the biochemical targets defined by the ESE guidelines (75). The best treatment option to reach these goals is still to be established.

\section{Quality of life}

Optimal control of HypoPT should not be restricted simply to restoring biochemical markers. In a number of chronic diseases, quality of life (QoL) of the patients is supposed to be a hallmark of therapy $(86,87,88)$ and is regarded as essential also for HypoPT patients by the ESE evidence-based guideline (7). Several instruments for the characterization of QoL in HypoPT patients were used, including the Short Form-36 (SF-36), the Hospital Anxiety and Depression Scale (HADS) and the WHO-5 WellBeing Index survey (WHO-5) (6, 68, 70, 71, 85). These different questionnaires revealed large deviations from the norms observed in the general population $(6,68,85)$. However, when involving patient control groups instead of population norms studies were less encouraging (67, 69). Also treatment studies using $\mathrm{rhPTH}[1-84]$ using the generic SF-36 tool proved unable to detect any difference in the quality of life when compared to a control group treated with placebo $(67,69,71)$. Symptoms of hypoparathyroidism are diverse and frequently hard to classify $(69,89)$. The knowledge and characterization of symptoms is thus essential to establish and validate tools that help to define optimal disease control $(7,90,91,92)$. Hence, the importance of hypoparathyroidism-specific instruments to assess symptoms has been regarded lately as crucial to improve our understanding of the nature and the degree of impairments to QoL $(71,90)$. These should also take into account patients' compliance with treatment which may be influenced by drug cost and a multiple tablet burden. Findings from a 13-Country patient survey highlight the substantial burden of illness that negatively impacts health-related QoL (HRQoL) and health status in patients with chronic HypoPT. The degree of HRQoL reduction reflected the magnitude of symptom severity reported by patients; the greater the symptom severity level, the lower the HRQoL (93). In addition, a disease characteristic questionnaire was developed in comparison with control groups (94). With these instruments, individual differences, and their relationship to biochemical variables (if any) and treatment modalities need to be investigated in the future to identify the best treatment option for the well-being of our patients. 


\section{Further perspectives and unmet needs in Chronic HypoPT in adults}

There has been an increasing awareness on chronic HypoPT in recent years, primarily driven by epidemiologic and systematic clinical studies focusing on QoL, morbidity and co-morbidities, as indicated in the newly published treatment guidelines $(7,66)$. Most patients do develop chronic HypoPT following neck surgery, and there is a need for a better understanding of the pathophysiology of post-thyroidectomy parathyroid failure $(95,96)$. As most of the current knowledge is based on cross-sectional or short-term intervention studies, prospective studies on modern treatment modalities are warranted and needed. Such studies should be based on strict diagnostic criteria and include prospectively defined endpoint also taking comorbidities and late complications into account. PTH replacement therapy has been marketed as adjunctive treatment of adult patients with chronic HypoPT, who cannot be adequately controlled with standard therapy alone. Intuitively, substitution with the missing hormone seems an attractive approach. However, data from randomized clinical trials (RCT) have so far only documented that PTH therapy lowers serum phosphate levels and doses of calcium supplements and activated vitamin D needed to maintain normocalcemia $(77,97)$. Neither an improved QoL, nor lowering of urine calcium has been documented in RCTs. Currently, only treatment regimens using once-a-day injections are available. Such regimens cause a sharp rise in plasma PTH levels. However, due to a short plasma-half life, PTH is only present in the circulation for $8-12 \mathrm{~h}$ after an injection. Data from studies using twice-a-day injections as well as continuous infusion by pump delivery have been publish showing a plasma profile more similar to normal physiology (98). Further studies are needed to elucidate the importance of different PTH treatment regimens on its effects.

More information on transition from childhood to adult care, on pregnancy and the early puerperium is essential. QoL seems to be very low in patients with chronic HypoPT, but so far mostly based on generic questionnaires, disease specific tools should be implemented, and also studies including the burden of symptoms as perceived from the patients perspective. The prospective and randomized clinical trials with QoL as an endpoint have so far not given a clear answer on the benefit of substitution with PTH as once-a-day injections compared with standard treatment $(69,99)$, a further unmet need at all levels. The future development of new technology for instant calcium determination which can be used by the patients themselves would not only support the intended studies but also help to better understand the significance of value control by the individual patient on their burden of symptoms.

\section{Primary hyperparathyroidism}

PHPT has become a common disease in developed countries, where the diagnosis often is made by chance in patients without specific symptoms, whereas the severe classical findings of PHPT most often are diagnosed in developing areas (100), potentially reflecting a real under diagnosing of the disease in these countries. With the change in clinical presentation, the question of management of asymptomatic patients (mild PHPT) has been discussed, often based on sparse evidence (101). Given PHPT as a common disease, most often in periand postmenopausal women $(1,2)$ with a prevalence of $2-5 \%$ in Scandinavian women, and most data derived from observational and case control studies, we will here concentrate on some areas of the disease spectrum that should be focused on in the immediate time to come.

\section{Qualitative aspects of bone tissue in PHPT}

Due to the high PTH levels (Fig. 4), bone turnover is increased in PHPT leading to an, in principle reversible bone loss based on the coupling principle and an enlargement of the remodeling space (102). Thereby, bone mass should be normalized by successful surgery and fracture frequency also be controlled. Based on large cohort studies, the fracture prevalence seemed to decrease compared to the pre-surgery situation in PHPT, but it was still increased compared the background population (103, 104). These data refer primarily to appendicular fractures, as vertebral fractures classically are underdiagnosed (101). Studies based on histomorphometry of iliac bone biopsies have indicated a preservation of trabecular bone, but also a trabecularization of the endosteal envelope leading to a thinning of the cortical shell $(105,106,107,108)$. In trabecular bone, the increased turnover is followed by an increase in the activation frequency, a shortening of the bone resorption period and of particular interest, a decrease in the resorption depth. The bone formation phase is also decreased, and the overall bone balance has been found to be even positive (reviewed in (102)). These findings are in accordance with an increased risk of peripheral fractures, but also indicating an unaltered or even reduced 


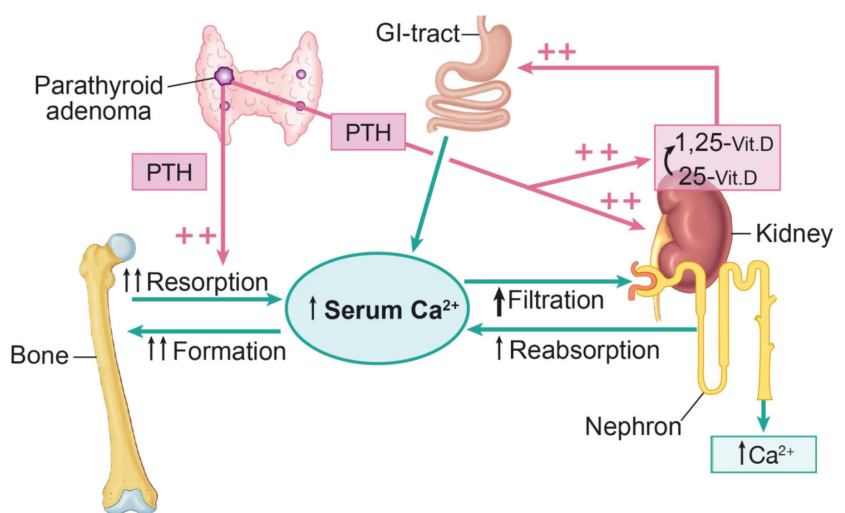

Figure 4

Overall calcium homeostasis in primary hyperparathyroidism. Due to a set-point error in PHPT, circulating PTH levels are inappropriately increased leading to a new steady state with increased PTH and calcium levels. Bone turnover, the renal tubular reabsorption of calcium, the activation of vitamin D followed by calcium absorption from the gut are all increased leading to the new steady state, which in principle is able to be regulated - just at a higher level.

risk of vertebral fractures, also in agreement with findings by DXA (102). Conversely, recent studies have found a high prevalence of vertebral fractures in patients of both sexes in both younger and older patients with PHPT, and even in patients with mild PHPT $(109,110)$. In the recent Danish study, the overall prevalence of vertebral fractures was around $22 \%$ for all age groups, and of interest higher in men compared with women in younger patients less than 60 years. Most of the fractures were mild to moderate and only $28.7 \%$ had severe fractures by the method of Genant $(111,112)$. When compared to patients with postmenopausal osteoporosis, patients with PHPT seemed to fracture at a higher BMD level (112). These findings are supported by microarchitectural analyses by HRpQCT imaging, showing decreased trabecular and cortical bone microstructure in active PHPT $(113,114)$. Randomized controlled studies have indicated a treatment effect of surgery on bone mass by DXA in the 5-year perspective, but not for cortical bone as seen in the proximal forearm $(115,116)$, of importance for the risk of low energy fracture (116). Microarchitectural analyses have supported these data, showing an improvement in bone mass indices in both trabecular and cortical bone by HRpQCT, starting already 6 month after surgical cure of PHPT in both sexes, and continuing up to 2 years following surgery (117). These improvements were attributed to a decrease in bone turnover and leading to a presumably increase in bone strength in both bone compartments, as demonstrated indirectly by finate element analyses (117).

\section{Is the cardiovascular burden increased in mild disease and potential reversible?}

Based on epidemiologic studies, PTH reflects cardiovascular (CV) risk in elderly men, even in the normal PTH range (118). PHPT is associated with a state of insulin resistance (119) and PTH is directly positively correlated to Left Ventricular Mass Index in PHPT (120). PHPT is also related to arterial hypertension, but reversibility by surgical treatment has not been demonstrated $(116,121$, 122). CV-mortality is increased in PTHP and a threshold effect for calcium levels has been discussed based on casecontrol studies $(104,123)$, below which an increased CV risk could not be demonstrated. A recent meta-analysis on the effect on echocardiography measures of surgical treatment in PHPT could not demonstrate signs of reversibility neither in observational nor randomized studies (124). The findings are in accordance with biochemical markers of insulin resistance and CV-risk based on 2 and 5-year data from the randomized Scandinavian study of PHPT $(121,125)$. Even though a positive treatment effect of surgery on vitamin D levels $(25(\mathrm{OH}) \mathrm{D})$ was demonstrated, no effect was seen on body composition and various measures of insulin resistance 5 years following randomization $(116,125)$.

The increased CV-risk in PHPT is influenced by traditional CV-risk factors and these might therefore partly explain the lack of reversibility of CV-endpoints by surgical treatment in PHPT (122). At the third international workshop on management of mild (asymptomatic) PHPT, it was stated that demonstration of CV-risk reversibility by surgery could change overall recommendations (126). Even though data from long term randomized studies have now emerged, the data have not indicated a change in the recommendations for management based on CV-risk. Thus, increased CV-risk is at present not considered to be an indication for parathyroidectomy in PHPT (11).

\section{Will patients with mild disease improve QoL with treatment?}

Patients with mild or asymptomatic PHPT have decreased QoL based on generic QoL questionnaires (2, 127, 128, $129,130)$. Numerous observational studies including the most recent have indicated a positive treatment effect of surgery on QoL $(131,132,133)$. Randomized controlled studies have shown ambiguous results $(128,129,130)$, 
demonstrating no significant effect of surgical treatment on QoL in patients not fulfilling the surgical criteria for PHPT, as summarized in a recent meta-analysis (134). A disease specific questionnaire (PHPQoL) has recently been developed (135). The tool seems reliable with good internal consistency and sensitive to changes over time. It was also demonstrated that PHPQoL correlated significantly with generic, traditional questionnaires and the tool was sensitive to the degree calcium related symptoms (135). So far the experience with PHPQoL tool is limited, but a recent observational study demonstrated an improvement in PHPQoL following parathyroidectomy, independent of calcium levels (136). PHPQoL has so far not been tested in randomized, controlled studies.

Due to ambiguous results from controlled studies and few data based on disease specific questionnaires, low QoL alone has not been an indication for surgical treatment of PHPT (11).

\section{Normocalcemic PHPT: How can the diagnosis be secured?}

Normocalcemic PHPT is defined by the finding of plasma PTH consistently (at least three determinations) elevated associated with normal total (albumin-corrected) and ionized calcium, after the exclusion of any other cause of secondary hyperparathyroidism:

(i) serum $25(\mathrm{OH}) \mathrm{D}<75 \mathrm{nmol} / \mathrm{l}$,

(ii) eGFR $<60 \mathrm{ml} / \mathrm{min}$ per $1.73 \mathrm{~m}^{2}$,

(iii) 24 -h urinary calcium $>8.75 \mathrm{mmol}(350 \mathrm{mg}$ ),

(iv) gastrointestinal disorders associated with calcium and/or vitamin D malabsorption, and

(v) medications that could alter calcium homeostasis, including lithium, thiazide- and loop-diuretics, bisphosphonates or Denosumab (137).

These patients should be distinguished from patients with classical hypercalcemic hyperparathyroidism, who occasionally may have normal total and ionized serum calcium. We should also remind that about $10-15 \%$ of patients with classic PHPT may have albumin-corrected serum calcium in the normal range, but elevated ionized calcium (138).

Several critical issues should be considered to secure the diagnosis of normocalcemic PHPT. The first problem is the definition of normocalcemia using the range of serum calcium in the normal population (usually $2.15-2.55 \mathrm{mmol} / \mathrm{l}(8.6-10.2 \mathrm{mg} / \mathrm{dl}))$. The individual variation in serum calcium is four times narrower that the inter individual variability, and for ionized calcium the variability is in the order of $0.02 \mathrm{mmol} / \mathrm{liter}$ (139). Thus, to be certain that the measured serum calcium is normal, we should know the range of variability of each individual subject. Therefore, facing a subject with the biochemical signature of normocalcemic PHPT, particularly when ionized calcium is in the upper normal range, we cannot exclude that the correct diagnosis could be classical PHPT, which is much more common than normocalcemic PHPT. Before making a definite diagnosis of normocalcemic PHPT, the patient must be replete for calcium and vitamin D intake for several weeks before the diagnostic sample. A second problem is the exclusion of secondary hyperparathyroidism, particularly when ionized calcium is in the lower normal range, on the basis of the cut-off values identified for serum $25(\mathrm{OH})$ D, eGFR and 24-h urinary calcium. The relationship between plasma PTH and each of these variables differs in different individuals. Therefore in the same individual, the coexistence of increased plasma PTH associated with values of serum $25(\mathrm{OH}) \mathrm{D}$ and eGFR above, and 24-h urinary calcium below the relative cut-offs, might be compatible with a form secondary hyperparathyroidism. A third problem is to exclude subtle gastrointestinal disorders that may cause calcium malabsorption. A fourth problem emerged from data from the Dallas Heart study, in which, after the exclusion of subjects with eGFR $<60 \mathrm{ml} / \mathrm{min}$ and thiazide diuretics and lithium use, the prevalence of normocalcemic PHPT dropped from 3.1\% to $0.6 \%$, when many of these subjects were reinvestigate 6 years later (137). Finally, a low calcium intake could also contribute to increasing plasma PTH. In conclusion cautions should be recommended before concluding that a biochemical signature translates into a disease entity. Nonetheless, these subjects should be followed because some of them may develop the classic hypercalcemic form of PHPT (140).

\section{Risk factors for nephrolithiasis and value of the 'biochemical urinary stone risk profile'}

Recent studies have shown an increasing prevalence (7-35\%) of silent kidney stones in patients with PHPT (112, 141). Hypercalciuria is a risk factor for nephrolithiasis and a higher mean urinary calcium excretion has been shown in patients with PHPT and kidney stones compared with those without (112). On the other hand, nephrolithiasis may occur in the absence of hypercalciuria, suggesting that factor(s) other than hypercalciuria may contribute to stone formation. In this regard, the latest guidelines for the management of asymptomatic PHPT recommend 
a more complete biochemical urinary stone risk profile evaluation, when 24-hour urinary calcium excretion is above $10 \mathrm{mmol}$ (400 mg) (11). The rational for choosing this cut-off value is unclear and does not consider that the upper limit of normal urinary calcium excretion differs between men and women $(7.5 \mathrm{mmol}$ vs $6.25 \mathrm{mmol}(300 \mathrm{mg}$ vs $250 \mathrm{mg}$ daily)). Tay et al. (142) recently reported that only $31.6 \%$ of patients with asymptomatic PHPT and occult nephrolithiasis had U-Ca $>10 \mathrm{mmol} / 24 \mathrm{~h}(400 \mathrm{mg} / 24 \mathrm{~h})$. Similarly, we found urinary calcium above this cut-off in 18 of 38 (47.4\%) patients with asymptomatic PHPT and silent nephrolithiasis (unpublished data), confirming a poor sensitivity of this cut-off. Therefore, the question arises, whether other cut-off values could be more appropriate. Some, but not all, studies in mixed cohorts of symptomatic and asymptomatic PHPT have shown that high $24 \mathrm{~h}$ urinary oxalate and low citrate excretion are associated with nephrolithiasis (143). Further studies with a more complete assessment of urinary parameters that might be involved in stone risk formation in patients with asymptomatic PHPT are warranted.

\section{Why are International guidelines not followed as expected?}

Cohort studies as well as retrospective reviews of group's records have shown that parathyroid surgery was performed in almost half of patients with symptomatic PHPT, in $30-40 \%$ of those with asymptomatic PHPT who met at least one criterion for surgery, and in about one quarter of patients with asymptomatic PHPT who did not meet any criterion for surgery $(144,145,146)$. A prospective study carried out in Italian tertiary referral centers in patients with newly diagnosed PHPT confirms that international guidelines are not obeyed over a follow-up period of one year after diagnosis. Indeed, parathyroidectomy was performed in $55.1 \%$ of patients with symptomatic PHPT and $53.7 \%$ of those with asymptomatic PHPT with at least one criterion for surgery. In both subgroups surveillance was advised when parathyroid imaging studies were negative. Parathyroidectomy was also performed in $25.7 \%$ of patients with asymptomatic PHPT and no surgical criteria, especially in those with positive parathyroid imaging studies (75\%) (147). Therefore, in view of the well-established selective approach to parathyroid surgery (148), imaging studies could be considered in the therapeutic decision-making process in patients with asymptomatic PHPT, as suggested by some guidelines $(149,150)$.

\section{Further perspectives and areas of uncertainty}

Although bone as target tissue has been a matter of clinical and scientific interest for decades, the biomechanical properties of bone in PHPT is still a matter of uncertainty and debate. The most recent studies have indicated increased risk of low energy fractures even in mild PHPT, but also that patients with PHPT might fracture at a higher BMD level than expected and compared with patients with postmenopausal osteoporosis (110). The continuous loss of bone mass in non-operated patients calls for consideration of a more active approach towards fracture protection, being surgery or antiresorptive therapy (115, $116)$, than recommended by the most recent international workshop (11). Another question arise when to start protective bone active treatment even before considering surgery both in classical or mild PHPT.

Several international guidelines and consensus reports have been published on the management of PHPT, and it is worrisome that the recommendations often not are followed. Recent long term data have emerged from randomized studies of mild PHPT without significantly demonstrating a treatment effect by surgery on CV-risk, presumable because of the importance of other CV-risk factors. Thus, at present the proposed threshold for calcium levels in PHPT given by epidemiologic studies has not been challenged. Most probably, the increased CV-risk is a combination of traditional risk factors for $\mathrm{CV}$ disease, and as well the increased calcium as PTH levels (151).

QoL is another area of controversy, as patients with PHPT have decreased scores by generic QoL tools and disease specific questionnaires only recently have been developed (135). So far, no benefit of parathyroidectomy on QoL from randomized studies has been demonstrated, and data from disease specific questionnaires are warranted.

\section{Discussions and conclusions}

The presentations and discussions from the first PARAT workshop held in Santpoort, The Netherlands in September 2018 are described in the present review, focusing on parathyroid disorders from an organ perspective with emphasis on unmet needs of importance for modern patient care.

Whereas benign parathyroid adenomas and hyperplasia are common in the clinic, PC are rarely seen and do call for special attention and transdisciplinary collaboration, the parathyroid surgeon and pathologist 
having central roles. The understanding of the pathogenesis and natural history of PC is virtually unknown. Due to the rareness, no center can claim high experience on $\mathrm{PC}$, and there is a need for central registries at different levels, for example through the European Reference Network on Rare Endocrine Conditions (ENDOERN). From the perspective of the PARAT project, such a registry should have priority, but it is equally important to join forces to increase experience and knowledge, and moreover to avoid parallel registries. Lessons should be learned for improving preoperative diagnosis, but at the moment no reliable biomarker for PC has been developed or validated. A multinational registry could be a way forward, also giving possibilities for second opinion at the histopathological level, and for long-term follow-up of patients.

There is an international need for stringent diagnosing of chronic HypoPT in adults, and we suggest following the ESE definition of low calcium levels with low or inappropriate low levels of PTH (7), where the chronic state refers to 6-month duration, but 12 months could be considered to allow recovery (96). There is a need for a better understanding of the role of in situ parathyroid gland preservation in the prevention of HypoPT following surgery and to gain knowledge on the potential parathyroid reserve $(95,152)$. The burden of HypoPT is high for the patient with impairment in QoL and cognitive properties, often with fluctuations within short time. There is a need for better understanding of the relation between biomarkers of the disease (calcium levels) and intellectual function, but also to establish the importance of the lacking hormone (PTH) in target tissues. The optimal individual target of serum calcium concentration to be reached with therapy (within the low-normal range) may be un-physiologic and cause symptoms by some, as the individual calcium level normally varies little within a narrow range. Preoperative serum calcium concentration could guide the management of patients with postsurgical HypoPt. Most patients with chronic HypoPT are females and in fertile age raising questions about optimal guidance during pregnancy and puerperium.

PHPT is a very common disease, especially in postmenopausal women (101). At present, we know little about the natural course of the disease in the modern clinic, and again it is virtually unknown whether morbidity and long-term outcome is related to the high calcium or PTH level or both (151). Cardiovascular morbidity is increased in PHPT, but potential reversibility by surgery is still a matter of debate and an issue for further research (122). Observation without intervention has been advocated for decades, but safely for how long time still remains to be answered. The natural history of fractures in PHPT is also controversial and need to be covered (112) in prospective studies. QoL is another controversial area in PHPT, where the recent developed disease specific questionnaire might be a step forward for a better understanding of the burden of the disease (135). Several international consensus statements on the management of PHPT have been published. With the accumulation of recent knowledge, a systematic and strictly evidence based clinical guideline should be considered.

\section{Declaration of interest}

The PARAT program of activities 2018-2019 has been supported by the European Society of Endocrinology (ESE) applying for and receiving an independent educational grant from Shire PLC. Shire has not had any opportunity to influence the agenda, planned activity schedule, choice of faculty, participants, venue, delivery formats, distribution profile of outcomes, scope of objectives or any other kind of engagement with the Steering Group or ESE Focus Area leads.

\section{Funding}

Further funding RVT is funded by a Wellcome Trust Senior Investigator Award (grant number 106995/Z/15/Z); National Institute for Health Research (NIHR) Oxford Biomedical Research Centre Program and an NIHR Senior Investigator Award (grant number NF-SI-0514-10091).

\section{Acknowledgements}

The PARAT Workshop Group, except the core writing authors listed on the front page: Andrea Guistina - San Raffaele Hospital, Milan, Italy (giustina. andrea@hsr.it). Wim Van Hul - Antwerp University Hospital, Belgium (wim.vanhul@uantwerpen.be). Karin Amrein - Medical University of Graz, Austria (karin.amrein@medunigraz.at). Tanja Sikjaer - Aarhus University Hospital, Denmark (Tanja.Sikjaer@aarhus.rm.dk). Elif Hindie - Bordeaux University Hospital, France (elif.hindie@chu-bordeaux.fr). Kyriakos Vamvakidis - Henry Dunant Hospital, Athens, Greece (info@drvamvakidis. gr). Sabrina Corbetta - University of Milan, Italy (sabrina.corbetta@unimi. it). Zhanna Balaia - National Medical Research Center for Endocrinology, Moscow, Russia (jannabelaya@gmail.com). Marianne Astor - Haukeland University Hospital, Bergen, Norway (marianne.catharina.astor@helsebergen.no). Ozer Makay - University Hospital, Izmir, Turkey (ozer.makay@ ege.edu.tr). Paul Newey - University of Dundee, UK (p.newey@dundee. ac.uk). Fadil Hannan - University of Liverpool, UK (Fadil.Hannan@liverpool. ac.uk). Lars Rolighed - Aarhus University Hospital, Denmark (larsroli@ rm.dk). Natasha Appelman-Dijkstra - Leiden University Medical Center, Netherlands (N.M.Appelman-Dijkstra@lumc.nl). Corrina Wicke - Thyroid Center, Kantonsspital, Lucerne, Switzerland (wickemedical@t-online.de). Stefan Pilz - Medical University of Graz, Austria (stefan.pilz@medunigraz. at). Federica Saponaro, University of Pisa, Italy (federica.saponaro@ gmail.com). Peter Vestergard, Aalborg University Hospital, Denmark (p.vestergaard@rn.dk)

\section{References}

1 Lundgren E, Rastad J, Thrufjell E, Akerstrom G \& Ljunghall S. Population-based screening for primary hyperparathyroidism with serum calcium and parathyroid hormone values in menopausal 
women. Surgery 1997121 287-294. (https://doi.org/10.1016/S00396060(97)90357-3)

2 Siilin H, Rastad J, Ljunggren O \& Lundgren E. Disturbances of calcium homeostasis consistent with mild primary hyperparathyroidism in premenopausal women and associated morbidity. Journal of Clinical Endocrinology and Metabolism 200893 47-53. (https://doi.org/10.1210/jc.2007-0600)

3 Wermers RA, Khosla S, Atkinson EJ, Achenbach SJ, Oberg AL, Grant CS \& Melton LJ 3rd. Incidence of primary hyperparathyroidism in Rochester, Minnesota, 1993-2001: an update on the changing epidemiology of the disease. Journal of Bone and Mineral Research 200621 171-177. (https://doi.org/10.1359/ JBMR.050910)

4 Wermers RA, Khosla S, Atkinson EJ, Hodgson SF, O'Fallon WM \& Melton LJ 3rd. The rise and fall of primary hyperparathyroidism: a population-based study in Rochester, Minnesota, 1965-1992. Annals of Internal Medicine 1997126 433-440. (https://doi. org/10.7326/0003-4819-126-6-199703150-00003)

5 Underbjerg L, Sikjaer T, Mosekilde L \& Rejnmark L. The epidemiology of nonsurgical hypoparathyroidism in Denmark: a nationwide case finding study. Journal of Bone and Mineral Research 201530 1738-1744. (https://doi.org/10.1002/jbmr.2501)

6 Astor MC, Lovas K, Debowska A, Eriksen EF, Evang JA, Fossum C, Fougner KJ, Holte SE, Lima K, Moe RB et al. Epidemiology and health-related quality of life in hypoparathyroidism in Norway. Journal of Clinical Endocrinology and Metabolism 2016101 3045-3053. (https://doi.org/10.1210/jc.2016-1477)

7 Bollerslev J, Rejnmark L, Marcocci C, Shoback DM, Sitges-Serra A, van Biesen W, Dekkers OM \& European Society of Endocrinology. European Society of Endocrinology Clinical Guideline: treatment of chronic hypoparathyroidism in adults. European Journal of Endocrinology 2015173 G1-G20. (https://doi.org/10.1530/EJE-150628)

8 Brown S, O'Neill C, Suliburk J, Sidhu S, Sywak M, Gill A, Robinson B \& Delbridge L. Parathyroid carcinoma: increasing incidence and changing presentation. ANZ Journal of Surgery 201181 528-532. (https://doi.org/10.1111/j.1445-2197.2010.05594.x)

9 Lee PK, Jarosek SL, Virnig BA, Evasovich M \& Tuttle TM. Trends in the incidence and treatment of parathyroid cancer in the United States. Cancer 2007109 1736-1741. (https://doi.org/10.1002/ cncr.22599)

10 Ryhanen EM, Leijon H, Metso S, Eloranta E, Korsoff P, Ahtiainen P, Kekalainen P, Tamminen M, Ristamaki R, Knutar O et al. A nationwide study on parathyroid carcinoma. Acta Oncologica 201756 991-1003. (https://doi.org/10.1080/0284186X.2017.1306103)

11 Bilezikian JP, Brandi ML, Eastell R, Silverberg SJ, Udelsman R, Marcocci C \& Potts JT Jr. Guidelines for the management of asymptomatic primary hyperparathyroidism: summary statement from the Fourth International Workshop. Journal of Clinical Endocrinology and Metabolism 201499 3561-3569. (https://doi. org/10.1210/jc.2014-1413)

12 Chou YH, Brown EM, Levi T, Crowe G, Atkinson AB, Arnqvist HJ, Toss G, Fuleihan GE, Seidman JG \& Seidman CE. The gene responsible for familial hypocalciuric hypercalcemia maps to chromosome 3q in four unrelated families. Nature Genetics $1992 \mathbf{1}$ 295-300. (https://doi.org/10.1038/ng0792-295)

13 Nesbit MA, Hannan FM, Howles SA, Reed AA, Cranston T, Thakker CE, Gregory L, Rimmer AJ, Rust N, Graham U et al. Mutations in AP2S1 cause familial hypocalciuric hypercalcemia type 3. Nature Genetics 201345 93-97. (https://doi.org/10.1038/ng.2492)

14 Thakker RV. Genetics of parathyroid tumours. Journal of Internal Medicine 2016280 574-583. (https://doi.org/10.1111/joim.12523)

15 Lo WM, Good ML, Nilubol N, Perrier ND \& Patel DT. Tumor size and presence of metastatic disease at diagnosis are associated with disease-specific survival in parathyroid carcinoma. Annals of Surgical
Oncology 201825 2535-2540. (https://doi.org/10.1245/s10434-0186559-6)

16 Shane E. Clinical review 122: parathyroid carcinoma. Journal of Clinical Endocrinology and Metabolism 200186 485-493. (https://doi. org/10.1210/jcem.86.2.7207)

17 Wei CH \& Harari A. Parathyroid carcinoma: update and guidelines for management. Current Treatment Options in Oncology 201213 11-23. (https://doi.org/10.1007/s11864-011-0171-3)

18 Cetani F, Pardi E \& Marcocci C. Update on parathyroid carcinoma. Journal of Endocrinological Investigation 201639 595-606. (https://doi. org/10.1007/s40618-016-0447-3)

19 Cardoso L, Stevenson M \& Thakker RV. Molecular genetics of syndromic and non-syndromic forms of parathyroid carcinoma. Human Mutation 201738 1621-1648. (https://doi.org/10.1002/ humu.23337)

20 Howell VM, Haven CJ, Kahnoski K, Khoo SK, Petillo D, Chen J, Fleuren GJ, Robinson BG, Delbridge LW, Philips J et al. HRPT2 mutations are associated with malignancy in sporadic parathyroid tumours. Journal of Medical Genetics 200340 657-663. (https://doi. org/10.1136/jmg.40.9.657)

21 Shattuck TM, Valimaki S, Obara T, Gaz RD, Clark OH, Shoback D, Wierman ME, Tojo K, Robbins CM, Carpten JD et al. Somatic and germ-line mutations of the HRPT2 gene in sporadic parathyroid carcinoma. New England Journal of Medicine 2003349 1722-1729. (https://doi.org/10.1056/NEJMoa031237)

22 Schulte KM \& Talat N. Diagnosis and management of parathyroid cancer. Nature Reviews: Endocrinology 20128 612-622. (https://doi. org/10.1038/nrendo.2012.102)

23 Cetani F, Frustaci G, Torregrossa L, Magno S, Basolo F, Campomori A, Miccoli P \& Marcocci C. A nonfunctioning parathyroid carcinoma misdiagnosed as a follicular thyroid nodule. World Journal of Surgical Oncology 201513 270. (https://doi. org/10.1186/s12957-015-0672-9)

24 Sidhu PS, Talat N, Patel P, Mulholland NJ \& Schulte KM. Ultrasound features of malignancy in the preoperative diagnosis of parathyroid cancer: a retrospective analysis of parathyroid tumours larger than 15 mm. European Radiology 201121 1865-1873. (https://doi. org/10.1007/s00330-011-2141-3)

25 Hara H, Igarashi A, Yano Y, Yashiro T, Ueno E, Aiyoshi Y, Ito K \& Obara T. Ultrasonographic features of parathyroid carcinoma. Endocrine Journal 200148 213-217. (https://doi.org/10.1507/ endocrj.48.213)

26 Christakis I, Vu T, Chuang HH, Fellman B, Figueroa AMS, Williams MD, Busaidy NL \& Perrier ND. The diagnostic accuracy of neck ultrasound, 4D-computed tomographyand sestamibi imaging in parathyroid carcinoma. European Journal of Radiology 201795 82-88. (https://doi.org/10.1016/j.ejrad.2017.07.026)

27 Andersen KF \& Albrecht-Beste E. Brown tumors due to primary hyperparathyroidism in a patient with parathyroid carcinoma mimicking skeletal metastases on (18)F-FDG PET/CT. Diagnostics $20155290-293$

28 Spinelli C, Bonadio AG, Berti P, Materazzi G \& Miccoli P. Cutaneous spreading of parathyroid carcinoma after fine needle aspiration cytology. Journal of Endocrinological Investigation 200023 255-257. (https://doi.org/10.1007/BF03343718)

29 Tomasetti C \& Vogelstein B. Cancer etiology. Variation in cancer risk among tissues can be explained by the number of stem cell divisions. Science 2015347 78-81. (https://doi.org/10.1126/science.1260825)

30 Christmas TJ, Chapple CR, Noble JG, Milroy EJ \& Cowie AG. Hyperparathyroidism after neck irradiation. British Journal of Surgery 198875 873-874. (https://doi.org/10.1002/bjs.1800750914)

31 Miki H, Sumitomo M, Inoue H, Kita S \& Monden Y. Parathyroid carcinoma in patients with chronic renal failure on maintenance hemodialysis. Surgery 1996120 897-901. (https://doi.org/10.1016/ S0039-6060(96)80101-2) 
32 Erickson LA \& Mete O. Immunohistochemistry in diagnostic parathyroid pathology. Endocrine Pathology 201829 113-129. (https://doi.org/10.1007/s12022-018-9527-6)

33 Cetani F, Banti C, Pardi E, Borsari S, Viacava P, Miccoli P, Torregrossa L, Basolo F, Pelizzo MR, Rugge M et al. CDC73 mutational status and loss of parafibromin in the outcome of parathyroid cancer. Endocrine Connections 20132 186-195. (https://doi.org/10.1530/ EC-13-0046)

34 Witteveen JE, Hamdy NA, Dekkers OM, Kievit J, van Wezel T, Teh BT, Romijn JA \& Morreau H. Downregulation of CASR expression and global loss of parafibromin staining are strong negative determinants of prognosis in parathyroid carcinoma. Modern Pathology 201124 688-697. (https://doi.org/10.1038/modpathol.2010.236)

35 Wang O, Wang C, Nie M, Cui Q, Guan H, Jiang Y, Li M, Xia W, Meng X \& Xing X. Novel HRPT2/CDC73 gene mutations and loss of expression of parafibromin in Chinese patients with clinically sporadic parathyroid carcinomas. PLOS ONE 20127 e45567. (https:// doi.org/10.1371/journal.pone.0045567)

36 Guarnieri V, Battista C, Muscarella LA, Bisceglia M, de Martino D, Baorda F, Maiello E, D'Agruma L, Chiodini I, Clemente C et al. CDC73 mutations and parafibromin immunohistochemistry in parathyroid tumors: clinical correlations in a single-centre patient cohort. Cellular Oncology 201235 411-422. (https://doi.org/10.1007/ s13402-012-0100-x)

37 Bricaire L, Odou MF, Cardot-Bauters C, Delemer B, North MO, Salenave S, Vezzosi D, Kuhn JM, Murat A, Caron P et al. Frequent large germline HRPT2 deletions in a French National cohort of patients with primary hyperparathyroidism. Journal of Clinical Endocrinology and Metabolism 201398 E403-E408. (https://doi. org/10.1210/jc.2012-2789)

38 van der Tuin K, Tops CMJ, Adank MA, Cobben JM, Hamdy NAT, Jongmans MC, Menko FH, van Nesselrooij BPM, Netea-Maier RT, Oosterwijk JC et al. CDC73-related disorders: clinical manifestations and case detection in primary hyperparathyroidism. Journal of Clinical Endocrinology and Metabolism 2017102 4534-4540.

39 Korpi-Hyovalti E, Cranston T, Ryhanen E, Arola J, Aittomaki K, Sane T, Thakker RV \& Schalin-Jantti C. CDC73 intragenic deletion in familial primary hyperparathyroidism associated with parathyroid carcinoma. Journal of Clinical Endocrinology and Metabolism 201499 3044-3048. (https://doi.org/10.1210/jc.2014-1481)

$40 \mathrm{Yu}$ W, McPherson JR, Stevenson M, van Eijk R, Heng HL, Newey P, Gan A, Ruano D, Huang D, Poon SL et al. Whole-exome sequencing studies of parathyroid carcinomas reveal novel PRUNE2 mutations, distinctive mutational spectra related to APOBEC-catalyzed DNA mutagenesis and mutational enrichment in kinases associated with cell migration and invasion. Journal of Clinical Endocrinology and Metabolism 2015100 E360-E364. (https://doi.org/10.1210/jc.2014-3238)

41 Pandya C, Uzilov AV, Bellizzi J, Lau CY, Moe AS, Strahl M, Hamou W, Newman LC, Fink MY, Antipin Y et al. Genomic profiling reveals mutational landscape in parathyroid carcinomas. JCI Insight 20172 e92061. (https://doi.org/10.1172/jci.insight.92061)

42 Schulte KM, Talat N, Galata G, Gilbert J, Miell J, Hofbauer LC, Barthel A, Diaz-Cano S \& Bornstein SR. Oncologic resection achieving r0 margins improves disease-free survival in parathyroid cancer. Annals of Surgical Oncology 201421 1891-1897. (https://doi. org/10.1245/s10434-014-3530-z)

43 Villar-del-Moral J, Jimenez-Garcia A, Salvador-Egea P, MartosMartinez JM, Nuno-Vazquez-Garza JM, Serradilla-Martin M, Gomez-Palacios A, Moreno-Llorente P, Ortega-Serrano J \& de la Quintana-Basarrate A. Prognostic factors and staging systems in parathyroid cancer: a multicenter cohort study. Surgery 2014156 1132-1144.

44 Storvall S, Ryhanen E, Bensch FV, Heiskanen I, Kytola S, Ebeling T, Makela S \& Schalin-Jantti C. Recurrent metastasized parathyroid carcinoma-long-term remission after combined treatments with surgery, radiotherapy, cinacalcet, zoledronic acid, and temozolomide. JBMR Plus 20193 e10114. (https://doi.org/10.1002/jbm4.10114)

45 Marcocci C, Cetani F, Rubin MR, Silverberg SJ, Pinchera A \& Bilezikian JP. Parathyroid carcinoma. Journal of Bone and Mineral Research 200823 1869-1880. (https://doi.org/10.1359/jbmr.081018)

46 Karuppiah D, Thanabalasingham G, Shine B, Wang LM, Sadler GP, Karavitaki N \& Grossman AB. Refractory hypercalcaemia secondary to parathyroid carcinoma: response to high-dose denosumab. European Journal of Endocrinology 2014171 K1-K5. (https://doi. org/10.1530/EJE-14-0166)

47 Thosani S \& Hu MI. Denosumab: a new agent in the management of hypercalcemia of malignancy. Future Oncology 201511 2865-2871. (https://doi.org/10.2217/fon.15.232)

48 Munson ND, Foote RL, Northcutt RC, Tiegs RD, Fitzpatrick LA, Grant CS, van Heerden JA, Thompson GB \& Lloyd RV. Parathyroid carcinoma: is there a role for adjuvant radiation therapy? Cancer 200398 2378-2384. (https://doi.org/10.1002/cncr.11819)

49 Rasmuson T, Kristoffersson A \& Boquist L. Positive effect of radiotherapy and surgery on hormonally active pulmonary metastases of primary parathyroid carcinoma. European Journal of Endocrinology 2000143 749-754. (https://doi.org/10.1530/ eje.0.1430749)

50 Tan AH, Kim HK, Kim MY, Oh YL, Kim JS, Chung JH \& Kim SW. Parathyroid carcinoma presenting as a hyperparathyroid crisis. Korean Journal of Internal Medicine 201227 229-231. (https://doi. org/10.3904/kjim.2012.27.2.229)

51 Bradwell AR \& Harvey TC. Control of hypercalcaemia of parathyroid carcinoma by immunisation. Lancet 1999353 370-373. (https://doi. org/10.1016/S0140-6736(98)06469-1)

52 Horie I, Ando T, Inokuchi N, Mihara Y, Miura S, Imaizumi M, Usa T, Kinoshita N, Sekine I, Kamihara S et al. First Japanese patient treated with parathyroid hormone peptide immunization for refractory hypercalcemia caused by metastatic parathyroid carcinoma. Endocrine Journal 201057 287-292. (https://doi.org/10.1507/endocrj.K09E-283)

53 Calandra DB, Chejfec G, Foy BK, Lawrence AM \& Paloyan E. Parathyroid carcinoma: biochemical and pathologic response to DTIC. Surgery 198496 1132-1137.

54 Yu YP, Liu P, Nelson J, Hamilton RL, Bhargava R, Michalopoulos G, Chen Q, Zhang J, Ma D, Pennathur A et al. Identification of recurrent fusion genes across multiple cancer types. Scientific Reports 20199 1074. (https://doi.org/10.1038/s41598-019-38550-6)

55 Bhangoo MS \& Sigal D. TRK inhibitors: clinical development of Larotrectinib. Current Oncology Reports 201921 14. (https://doi. org/10.1007/s11912-019-0761-y)

56 Kang H, Pettinga D, Schubert AD, Ladenson PW, Ball DW, Chung JH, Schrock AB, Madison R, Frampton GM, Stephens PJ et al. Genomic profiling of parathyroid carcinoma reveals genomic alterations suggesting benefit from therapy. Oncologist 201924 791-797. (https://doi.org/10.1634/theoncologist.2018-0334)

57 Cui M, Hu Y, Bi Y, Wang W, Wang M, Zhang X, Zhang R, Wang P, Su Z, Gao X et al. Preliminary exploration of potential molecular therapeutic targets in recurrent and metastatic parathyroid carcinomas. International Journal of Cancer 2019144 525-532. (https://doi.org/10.1002/ijc.31948)

58 Ribas A \& Wolchok JD. Cancer immunotherapy using checkpoint blockade. Science 2018359 1350-1355. (https://doi.org/10.1126/ science.aar4060)

59 Samstein RM, Lee CH, Shoushtari AN, Hellmann MD, Shen R, Janjigian YY, Barron DA, Zehir A, Jordan EJ, Omuro A et al. Tumor mutational load predicts survival after immunotherapy across multiple cancer types. Nature Genetics 201951 202-206. (https://doi. org/10.1038/s41588-018-0312-8)

60 Costa-Guda J. Commentary: next-generation sequence analysis of parathyroid carcinoma. Journal of the Endocrine Society 20193 560-562. (https://doi.org/10.1210/js.2018-00315) 
61 Schettini F, De Santo I, Rea CG, De Placido P, Formisano L, Giuliano M, Arpino G, De Laurentiis M, Puglisi F, De Placido S et al. CDK 4/6 inhibitors as single agent in advanced solid tumors. Frontiers in Oncology 20188 608. (https://doi.org/10.3389/fonc.2018.00608)

62 Cetani F, Pardi E \& Marcocci C. Parathyroid carcinoma. Frontiers of Hormone Research 201951 63-76. (https://doi. org/10.1159/000491039)

63 Clarke CN, Katsonis P, Hsu TK, Koire AM, Silva-Figueroa A, Christakis I, Williams MD, Kutahyalioglu M, Kwatampora L, Xi Y et al. Comprehensive genomic characterization of parathyroid cancer identifies novel candidate driver mutations and core pathways. Journal of the Endocrine Society 20193 544-559. (https://doi. org/10.1210/js.2018-00043)

64 Clarke BL. Epidemiology and complications of hypoparathyroidism. Endocrinology and Metabolism Clinics of North America 201847 771-782. (https://doi.org/10.1016/j.ecl.2018.07.004)

65 Underbjerg L, Sikjaer T, Mosekilde L \& Rejnmark L. Cardiovascular and renal complications to postsurgical hypoparathyroidism: a Danish nationwide controlled historic follow-up study. Journal of Bone and Mineral Research 201328 2277-2285. (https://doi. org/10.1002/jbmr.1979)

66 Brandi ML, Bilezikian JP, Shoback D, Bouillon R, Clarke BL, Thakker RV, Khan AA \& Potts JT Jr. Management of hypoparathyroidism: summary statement and guidelines. Journal of Clinical Endocrinology and Metabolism 2016101 2273-2283. (https:// doi.org/10.1210/jc.2015-3907)

67 Arlt W, Fremerey C, Callies F, Reincke M, Schneider P, Timmermann W \& Allolio B. Well-being, mood and calcium homeostasis in patients with hypoparathyroidism receiving standard treatment with calcium and vitamin D. European Journal of Endocrinology 2002146 215-222. (https://doi.org/10.1530/ eje.0.1460215)

68 Cusano NE, Rubin MR, McMahon DJ, Irani D, Anderson L, Levy E, Bilezikian JP. PTH(1-84) is associated with improved quality of life in hypoparathyroidism through 5 years of therapy. Journal of Clinical Endocrinology and Metabolism 201499 3694-3699. (https://doi. org/10.1210/jc.2014-2267)

69 Sikjaer T, Rolighed L, Hess A, Fuglsang-Frederiksen A, Mosekilde L \& Rejnmark L. Effects of PTH(1-84) therapy on muscle function and quality of life in hypoparathyroidism: results from a randomized controlled trial. Osteoporosis International 201425 1717-1726. (https://doi.org/10.1007/s00198-014-2677-6)

70 Underbjerg L, Sikjaer T \& Rejnmark L. Health-related quality of life in patients with nonsurgical hypoparathyroidism and pseudohypoparathyroidism. Clinical Endocrinology $2018 \mathbf{8 8}$ 838-847. (https://doi.org/10.1111/cen.13593)

71 Vokes T. Quality of life in hypoparathyroidism. Bone 2019120 542-547. (https://doi.org/10.1016/j.bone.2018.09.017)

72 Bilezikian JP, Khan A, Potts JT Jr, Brandi ML, Clarke BL, Shoback D, Juppner H, D'Amour P, Fox J, Rejnmark L et al. Hypoparathyroidism in the adult: epidemiology, diagnosis, pathophysiology, targetorgan involvement, treatment, and challenges for future research. Journal of Bone and Mineral Research 201126 2317-2337. (https://doi. org/10.1002/jbmr.483)

73 Mehanna HM, Jain A, Randeva H, Watkinson J \& Shaha A. Postoperative hypocalcemia - the difference a definition makes. Head and Neck 201032 279-283.

74 Harslof T, Rolighed L \& Rejnmark L. Huge variations in definition and reported incidence of postsurgical hypoparathyroidism: a systematic review. Endocrine 201964 176-183. (https://doi. org/10.1007/s12020-019-01858-4)

75 Meola A, Vignali E, Matrone A, Cetani F \& Marcocci C. Efficacy and safety of long-term management of patients with chronic postsurgical hypoparathyroidism. Journal of Endocrinological Investigation 201841 1221-1226. (https://doi.org/10.1007/s40618-018-0857-5)
76 Lerolle N, Lantz B, Paillard F, Gattegno B, Flahault A, Ronco P, Houillier P \& Rondeau E. Risk factors for nephrolithiasis in patients with familial idiopathic hypercalciuria. American Journal of Medicine 2002113 99-103. (https://doi.org/10.1016/S0002-9343(02)01152-X)

77 Sikjaer T, Rejnmark L, Rolighed L, Heickendorff L, Mosekilde L \& Hypoparathyroid Study Group. The effect of adding PTH(1-84) to conventional treatment of hypoparathyroidism: a randomized, placebo-controlled study. Journal of Bone and Mineral Research 2011 26 2358-2370. (https://doi.org/10.1002/jbmr.470)

78 Mitchell DM, Regan S, Cooley MR, Lauter KB, Vrla MC, Becker CB, Burnett-Bowie SA \& Mannstadt M. Long-term follow-up of patients with hypoparathyroidism. Journal of Clinical Endocrinology and Metabolism 201297 4507-4514. (https://doi.org/10.1210/jc.2012-1808)

79 Peacock M, Robertson WG \& Nordin BE. Relation between serum and urinary calcium with particular reference to parathyroid activity. Lancet 19691 384-386. (https://doi.org/10.1016/S01406736(69)91353-1)

80 Porter RH, Cox BG, Heaney D, Hostetter TH, Stinebaugh BJ \& Suki WN. Treatment of hypoparathyroid patients with chlorthalidone. New England Journal of Medicine 1978298 577-581. (https://doi.org/10.1056/NEJM197803162981101)

81 Fink HA, Wilt TJ, Eidman KE, Garimella PS, MacDonald R, Rutks IR, Brasure M, Kane RL, Ouellette J \& Monga M. Medical management to prevent recurrent nephrolithiasis in adults: a systematic review for an American College of Physicians Clinical Guideline. Annals of Internal Medicine 2013158 535-543. (https://doi.org/10.7326/0003-4819158-7-201304020-00005)

82 Carbone LD, Bush AJ, Barrow KD \& Kang AH. The relationship of sodium intake to calcium and sodium excretion and bone mineral density of the hip in postmenopausal African-American and Caucasian women. Journal of Bone and Mineral Metabolism 200321 415-420. (https://doi.org/10.1007/s00774-003-0437-3)

83 Underbjerg L, Sikjaer T \& Rejnmark L. Long-term complications in patients with hypoparathyroidism evaluated by biochemical findings: a case-control study. Journal of Bone and Mineral Research 201833 822-831. (https://doi.org/10.1002/jbmr.3368)

84 Underbjerg L, Sikjaer T, Mosekilde L \& Rejnmark L. Postsurgical hypoparathyroidism - risk of fractures, psychiatric diseases, cancer, cataract, and infections. Journal of Bone and Mineral Research 201429 2504-2510. (https://doi.org/10.1002/jbmr.2273)

85 Sikjaer T, Moser E, Rolighed L, Underbjerg L, Bislev LS, Mosekilde L \& Rejnmark L. Concurrent hypoparathyroidism is associated with impaired physical function and quality of life in hypothyroidism. Journal of Bone and Mineral Research 201631 1440-1448. (https://doi. org/10.1002/jbmr.2812)

86 Kuznetsov L, Griffin SJ, Davies MJ, Lauritzen T, Khunti K, Rutten GE $\&$ Simmons RK. Diabetes-specific quality of life but not health status is independently associated with glycaemic control among patients with type 2 diabetes: a cross-sectional analysis of the ADDITIONEurope trial cohort. Diabetes Research and Clinical Practice 2014104 281-287. (https://doi.org/10.1016/j.diabres.2013.12.029)

87 Porcu S \& Mandas A. How to evaluate quality of life. Monaldi Archives for Chest Disease 201989 59-61. (https://doi.org/10.4081/ monaldi.2019.1033)

88 Jitender S, Mahajan R, Rathore V \& Choudhary R. Quality of life of cancer patients. Journal of Experimental Therapeutics and Oncology 201812 217-221.

89 Cho NL, Moalem J, Chen L, Lubitz CC, Moore FD Jr \& Ruan DT. Surgeons and patients disagree on the potential consequences from hypoparathyroidism. Endocrine Practice 201420 427-446. (https:// doi.org/10.4158/EP13321.OR)

90 Mannstadt M, Bilezikian JP, Thakker RV, Hannan FM, Clarke BL, Rejnmark L, Mitchell DM, Vokes TJ, Winer KK \& Shoback DM. Hypoparathyroidism. Nature Reviews Disease Primers 2017317055. (https://doi.org/10.1038/nrdp.2017.55) 
91 Shoback DM, Bilezikian JP, Costa AG, Dempster D, Dralle H, Khan AA, Peacock M, Raffaelli M, Silva BC, Thakker RV et al. Presentation of hypoparathyroidism: etiologies and clinical features. Journal of Clinical Endocrinology and Metabolism 2016101 2300-2312. (https://doi.org/10.1210/jc.2015-3909)

92 Clarke BL, Brown EM, Collins MT, Juppner H, Lakatos P, Levine MA, Mannstadt MM, Bilezikian JP, Romanischen AF \& Thakker RV. Epidemiology and diagnosis of hypoparathyroidism. Journal of Clinical Endocrinology and Metabolism 2016101 2284-2299. (https:// doi.org/10.1210/jc.2015-3908)

93 Siggelkow H, Clarke BL, Germak J, Marelli C, Chen K, DahlHansen H, Glenister E, Bent-Ennakhil N, Judge D, Gibson K et al. MON-521 impact of chronic hypoparathyroidism on health-related quality of life: findings from a 13-country patient survey. Journal of the Endocrine Society 20193 MON-521. (https://doi.org/10.1210/ js.2019-MON-521)

94 Wilde D, Wilken L, Stamm B, Happner C, Leha A, HermannLingen C \& Siggelkov H. Use of a disease-characteristic questionnaire identified pain and cramps and neuro-vegetative symptoms as significantly elevated and affected by medication in mainly wellcontrolled hypoparathyroid patients. Endocrine Abstracts 201856 GP 182. (https://doi.org/10.1530/endoabs.56.GP182)

95 Sitges-Serra A, Gomez J, Barczynski M, Lorente-Poch L, Iacobone M $\&$ Sancho J. A nomogram to predict the likelihood of permanent hypoparathyroidism after total thyroidectomy based on delayed serum calcium and iPTH measurements. Gland Surgery 20176 S11-S19. (https://doi.org/10.21037/gs.2017.10.04)

96 Villarroya-Marquina I, Sancho J, Lorente-Poch L, Gallego-Otaegui L $\&$ Sitges-Serra A. Time to parathyroid function recovery in patients with protracted hypoparathyroidism after total thyroidectomy. European Journal of Endocrinology 2018178 103-111. (https://doi. org/10.1530/EJE-17-0589)

97 Mannstadt M, Clarke BL, Vokes T, Brandi ML, Ranganath L, Fraser WD, Lakatos P, Bajnok L, Garceau R, Mosekilde L et al. Efficacy and safety of recombinant human parathyroid hormone (1-84) in hypoparathyroidism (REPLACE): a double-blind, placebo-controlled, randomised, phase 3 study. Lancet: Diabetes and Endocrinology 20131 275-283. (https://doi.org/10.1016/S2213-8587(13)70106-2)

98 Winer KK, Zhang B, Shrader JA, Peterson D, Smith M, Albert PS \& Cutler GB Jr. Synthetic human parathyroid hormone 1-34 replacement therapy: a randomized crossover trial comparing pump versus injections in the treatment of chronic hypoparathyroidism. Journal of Clinical Endocrinology and Metabolism 201297 391-399. (https://doi.org/10.1210/jc.2011-1908)

99 Vokes TJ, Mannstadt M, Levine MA, Clarke BL, Lakatos P, Chen K, Piccolo R, Krasner A, Shoback DM \& Bilezikian JP. Recombinant human parathyroid hormone effect on health-related quality of life in adults with chronic hypoparathyroidism. Journal of Clinical Endocrinology and Metabolism 2018103 722-731. (https://doi. org/10.1210/jc.2017-01471)

100 Khan AA, Hanley DA, Rizzoli R, Bollerslev J, Young JE, Rejnmark L, Thakker R, D'Amour P, Paul T, Van Uum S et al. Primary hyperparathyroidism: review and recommendations on evaluation, diagnosis, and management. A Canadian and International Consensus. Osteoporosis International 201728 1-19. (https://doi. org/10.1007/s00198-016-3716-2)

101 Bollerslev J, Marcocci C, Sosa M, Nordenstrom J, Bouillon R \& Mosekilde L. Current evidence for recommendation of surgery, medical treatment and vitamin D repletion in mild primary hyperparathyroidism. European Journal of Endocrinology 2011165 851-864. (https://doi.org/10.1530/EJE-11-0589)

102 Mosekilde L. Primary hyperparathyroidism and the skeleton. Clinical Endocrinology 200869 1-19. (https://doi.org/10.1111/j.13652265.2007.03162.x)

103 Vestergaard P, Mollerup CL, Frokjaer VG, Christiansen P, BlichertToft M \& Mosekilde L. Cohort study of risk of fracture before and after surgery for primary hyperparathyroidism. BMJ $2000 \mathbf{3 2 1}$ 598-602. (https://doi.org/10.1136/bmj.321.7261.598)

104 Vestergaard P \& Mosekilde L. Cohort study on effects of parathyroid surgery on multiple outcomes in primary hyperparathyroidism. BMJ 2003327 530-534. (https://doi.org/10.1136/bmj.327.7414.530)

105 Christiansen P, Steiniche T, Brockstedt H, Mosekilde L, Hessov I \& Melsen F. Primary hyperparathyroidism: iliac crest cortical thickness, structure and remodeling evaluated by histomorphometric methods. Aarhus Bone and Mineral Research Group. Bone 199314 403-408. (https://doi.org/10.1016/8756-3282(93)90171-6)

106 Christiansen P, Steiniche T, Vesterby A, Mosekilde L, Hessov I \& Melsen F. Primary hyperparathyroidism: iliac crest trabecular bone volume, structure, remodeling, and balance evaluated by histomorphometric methods. Bone 199213 41-49. (https://doi. org/10.1016/8756-3282(92)90360-9)

107 Steiniche T, Christiansen P, Vesterby A, Ullerup R, Hessov I, Mosekilde LE \& Melsen F. Primary hyperparathyroidism: bone structure, balance, and remodeling before and 3 years after surgical treatment. Bone 200026 535-543. (https://doi.org/10.1016/S87563282(00)00260-X)

108 Parisien M, Silverberg SJ, Shane E, de la Cruz L, Lindsay R, Bilezikian JP \& Dempster DW. The histomorphometry of bone in primary hyperparathyroidism: preservation of cancellous bone structure. Journal of Clinical Endocrinology and Metabolism 199070 930-938. (https://doi.org/10.1210/jcem-70-4-930)

109 Vignali E, Viccica G, Diacinti D, Cetani F, Cianferotti L, Ambrogini E, Banti C, Del Fiacco R, Bilezikian JP, Pinchera A et al. Morphometric vertebral fractures in postmenopausal women with primary hyperparathyroidism. Journal of Clinical Endocrinology and Metabolism 200994 2306-2312. (https://doi.org/10.1210/jc.2008-2006)

110 Ejlsmark-Svensson H, Bislev LS, Lajlev S, Harslof T, Rolighed L, Sikjaer T \& Rejnmark L. Prevalence and risk of vertebral fractures in primary hyperparathyroidism: a nested case-control study. Journal of Bone and Mineral Research 201833 1657-1664. (https://doi. org/10.1002/jbmr.3461)

111 Genant HK, Li J, Wu CY \& Shepherd JA. Vertebral fractures in osteoporosis: a new method for clinical assessment. Journal of Clinical Densitometry 20003 281-290. (https://doi.org/10.1385/JCD:3:3:281)

112 Ejlsmark-Svensson H, Bislev LS, Rolighed L, Sikjaer T \& Rejnmark L. Predictors of renal function and calcifications in primary hyperparathyroidism: a nested case-control study. Journal of Clinical Endocrinology and Metabolism 2018103 3574-3583. (https://doi. org/10.1210/jc.2018-00923)

113 Hansen S, Beck Jensen JE, Rasmussen L, Hauge EM \& Brixen K. Effects on bone geometry, density, and microarchitecture in the distal radius but not the tibia in women with primary hyperparathyroidism: a case-control study using HR-pQCT. Journal of Bone and Mineral Research 201025 1941-1947. (https://doi.org/10.1002/jbmr.98)

114 Stein EM, Silva BC, Boutroy S, Zhou B, Wang J, Udesky J, Zhang C, McMahon DJ, Romano M, Dworakowski E et al. Primary hyperparathyroidism is associated with abnormal cortical and trabecular microstructure and reduced bone stiffness in postmenopausal women. Journal of Bone and Mineral Research 2013 28 1029-1040. (https://doi.org/10.1002/jbmr.1841)

115 Lundstam K, Heck A, Godang K, Mollerup C, Baranowski M, Pernow Y, Aas T, Hessman O, Rosen T, Nordenstrom J et al. Effect of surgery versus observation: skeletal 5-year outcomes in a randomized trial of patients with primary HPT (the SIPH Study). Journal of Bone and Mineral Research 201732 1907-1914. (https://doi.org/10.1002/ jbmr.3177)

116 Lundstam K, Heck A, Mollerup C, Godang K, Baranowski M, Pernow Y, Varhaug JE, Hessman O, Rosen T, Nordenstrom J et al. Effects of parathyroidectomy versus observation on the development of vertebral fractures in mild primary hyperparathyroidism. Journal of Clinical Endocrinology and Metabolism 2015100 1359-1367. (https:// doi.org/10.1210/jc.2014-3441) 
117 Cusano NE, Rubin MR, Silva BC, Tay YD, Williams JM, Agarwal S, Omeragic B, Guo XE \& Bilezikian JP. Skeletal microstructure and estimated bone strength improve following parathyroidectomy in primary hyperparathyroidism. Journal of Clinical Endocrinology and Metabolism 2018103 196-205. (https://doi.org/10.1210/jc.201701932)

118 Hagstrom E, Hellman P, Larsson TE, Ingelsson E, Berglund L, Sundstrom J, Melhus H, Held C, Lind L, Michaelsson K et al. Plasma parathyroid hormone and the risk of cardiovascular mortality in the community. Circulation 2009119 2765-2771. (https://doi. org/10.1161/CIRCULATIONAHA.108.808733)

119 Bolland MJ, Grey AB, Gamble GD \& Reid IR. Association between primary hyperparathyroidism and increased body weight: a metaanalysis. Journal of Clinical Endocrinology and Metabolism 200590 1525-1530. (https://doi.org/10.1210/jc.2004-1891)

120 Persson A, Bollerslev J, Rosen T, Mollerup CL, Franco C, Isaksen GA, Ueland T, Jansson S, Caidahl K \& SIPH Study Group. Effect of surgery on cardiac structure and function in mild primary hyperparathyroidism. Clinical Endocrinology 201174 174-180. (https://doi.org/10.1111/j.1365-2265.2010.03909.x)

121 Bollerslev J, Rosen T, Mollerup CL, Nordenstrom J, Baranowski M, Franco C, Pernow Y, Isaksen GA, Godang K, Ueland T et al. Effect of surgery on cardiovascular risk factors in mild primary hyperparathyroidism. Journal of Clinical Endocrinology and Metabolism 200994 2255-2261. (https://doi.org/10.1210/jc.2008-2742)

122 Walker MD \& Silverberg SJ. Primary hyperparathyroidism. Nature Reviews: Endocrinology 201814 115-125. (https://doi.org/10.1038/ nrendo.2017.104)

123 Vestergaard P, Mollerup CL, Frokjaer VG, Christiansen P, BlichertToft M \& Mosekilde L. Cardiovascular events before and after surgery for primary hyperparathyroidism. World Journal of Surgery 200327 216-222. (https://doi.org/10.1007/s00268-002-6541-z)

124 Best CAE, Krishnan R, Malvankar-Mehta MS \& MacNeil SD. Echocardiogram changes following parathyroidectomy for primary hyperparathyroidism: a systematic review and metaanalysis. Medicine 201796 e7255. (https://doi.org/10.1097/ MD.0000000000007255)

125 Godang K, Lundstam K, Mollerup C, Fougner SL, Pernow Y, Nordenstrom J, Rosen T, Jansson S, Hellstrom M, Bollerslev J et al. The effect of surgery on fat mass, lipid and glucose metabolism in mild primary hyperparathyroidism. Endocrine Connections 20187 941-948. (https://doi.org/10.1530/EC-18-0259)

126 Silverberg SJ, Lewiecki EM, Mosekilde L, Peacock M \& Rubin MR. Presentation of asymptomatic primary hyperparathyroidism: proceedings of the third international workshop. Journal of Clinical Endocrinology and Metabolism 200994 351-365. (https://doi. org/10.1210/jc.2008-1760)

127 Lundgren E, Ljunghall S, Akerstrom G, Hetta J, Mallmin H $\&$ Rastad J. Case-control study on symptoms and signs of 'asymptomatic' primary hyperparathyroidism. Surgery $1998 \mathbf{1 2 4}$ 980-985; discussion 985-986. (https://doi.org/10.1016/S00396060(98)70038-8)

128 Ambrogini E, Cetani F, Cianferotti L, Vignali E, Banti C, Viccica G, Oppo A, Miccoli P, Berti P, Bilezikian JP et al. Surgery or surveillance for mild asymptomatic primary hyperparathyroidism: a prospective, randomized clinical trial. Journal of Clinical Endocrinology and Metabolism 200792 3114-3121. (https://doi.org/10.1210/jc.20070219)

129 Bollerslev J, Jansson S, Mollerup CL, Nordenstrom J, Lundgren E, Torring O, Varhaug JE, Baranowski M, Aanderud S, Franco C et al. Medical observation, compared with parathyroidectomy, for asymptomatic primary hyperparathyroidism: a prospective, randomized trial. Journal of Clinical Endocrinology and Metabolism 200792 1687-1692. (https://doi.org/10.1210/jc.2006-1836)

130 Rao DS, Phillips ER, Divine GW \& Talpos GB. Randomized controlled clinical trial of surgery versus no surgery in patients with mild asymptomatic primary hyperparathyroidism. Journal of Clinical Endocrinology and Metabolism 200489 5415-5422. (https://doi. org/10.1210/jc.2004-0028)

131 Bannani S, Christou N, Guerin C, Hamy A, Sebag F, Mathonnet M, Guillot P, Caillard C, Blanchard C \& Mirallie E. Effect of parathyroidectomy on quality of life and non-specific symptoms in normocalcaemic primary hyperparathyroidism. British Journal of Surgery 2018105 223-229. (https://doi.org/10.1002/bjs.10739)

132 Weber T, Eberle J, Messelhauser U, Schiffmann L, Nies C, Schabram J, Zielke A, Holzer K, Rottler E, Henne-Bruns D et al. Parathyroidectomy, elevated depression scores, and suicidal ideation in patients with primary hyperparathyroidism: results of a prospective multicenter study. JAMA Surgery 2013148 109-115. (https://doi.org/10.1001/2013.jamasurg.316)

133 Storvall S, Ryhanen EM, Heiskanen I, Sintonen H, Roine RP \& Schalin-Jantti C. Surgery significantly improves neurocognition, sleep, and blood pressure in primary hyperparathyroidism: a 3-year prospective follow-up study. Hormone and Metabolic Research 201749 772-777. (https://doi.org/10.1055/s-0043-118347)

134 Cheng SP, Lee JJ, Liu TP, Yang PS, Liu SC, Hsu YC \& Liu CL. Quality of life after surgery or surveillance for asymptomatic primary hyperparathyroidism: a meta-analysis of randomized controlled trials. Medicine 201594 e931. (https://doi.org/10.1097/ MD.0000000000000931)

135 Webb SM, Puig-Domingo M, Villabona C, Munoz-Torres M, Marazuela M, Fernandez D, Martinez G, Jodar E, Mangas MA, Perulero N et al. Validation of PHPQoL, a disease-specific quality-oflife questionnaire for patients with primary hyperparathyroidism. Journal of Clinical Endocrinology and Metabolism 2016101 1571-1578. (https://doi.org/10.1210/jc.2015-3094)

136 Ejlsmark-Svensson H, Sikjaer T, Webb SM, Rejnmark L \& Rolighed L. Health-related quality of life improves 1 year after parathyroidectomy in primary hyperparathyroidism: a prospective cohort study. Clinical Endocrinology 201990 184-191. (https://doi. org/10.1111/cen.13865)

137 Cusano NE, Silverberg SJ \& Bilezikian JP. Normocalcemic primary hyperparathyroidism. Journal of Clinical Densitometry 201316 33-39. (https://doi.org/10.1016/j.jocd.2012.12.001)

138 Ong GS, Walsh JP, Stuckey BG, Brown SJ, Rossi E, Ng JL, Nguyen HH, Kent GN \& Lim EM. The importance of measuring ionized calcium in characterizing calcium status and diagnosing primary hyperparathyroidism. Journal of Clinical Endocrinology and Metabolism 201297 3138-3145. (https://doi.org/10.1210/jc.2012-1429)

139 Pedersen KO. On the cause and degree of intraindividual serum calcium variability. Scandinavian Journal of Clinical and Laboratory Investigation 197230 191-199. (https://doi. org/10.3109/00365517209081110)

140 Lowe H, McMahon DJ, Rubin MR, Bilezikian JP \& Silverberg SJ. Normocalcemic primary hyperparathyroidism: further characterization of a new clinical phenotype. Journal of Clinical Endocrinology and Metabolism 200792 3001-3005. (https://doi. org/10.1210/jc.2006-2802)

141 Suh JM, Cronan JJ \& Monchik JM. Primary hyperparathyroidism: is there an increased prevalence of renal stone disease? American Journal of Roentgenology 2008191 908-911. (https://doi.org/10.2214/ AJR.07.3160)

142 Tay YD, Liu M, Bandeira L, Bucovsky M, Lee JA, Silverberg SJ $\&$ Walker MD. Occult urolithiasis in asymptomatic primary hyperparathyroidism. Endocrine Research 201843 106-115. (https:// doi.org/10.1080/07435800.2018.1431275)

143 Rejnmark L, Vestergaard P \& Mosekilde L. Nephrolithiasis and renal calcifications in primary hyperparathyroidism. Journal of Clinical Endocrinology and Metabolism 201196 2377-2385. (https://doi. org/10.1210/jc.2011-0569)

144 Yeh MW, Wiseman JE, Ituarte PH, Pasternak JD, Hwang RS, Wu B, Liu IL \& Haigh PI. Surgery for primary hyperparathyroidism: are the 
consensus guidelines being followed? Annals of Surgery 2012255 1179-1183. (https://doi.org/10.1097/SLA.0b013e31824dad7d)

145 Trombetti A, Christ ER, Henzen C, Gold G, Brandle M,

Herrmann FR, Torriani C, Triponez F, Kraenzlin M, Rizzoli R et al. Clinical presentation and management of patients with primary hyperparathyroidism of the Swiss Primary Hyperparathyroidism Cohort: a focus on neuro-behavioral and cognitive symptoms. Journal of Endocrinological Investigation 201639 567-576. (https://doi. org/10.1007/s40618-015-0423-3)

146 Sharata A, Kelly TL, Rozenfeld Y, Hammill CW, Schuman E, Carlisle JR \& Aliabadi-Wahle S. Management of primary hyperparathyroidism: can we do better? American Surgeon 201783 64-70.

147 Saponaro F, Cetani F, Repaci A, Pagotto U, Cipriani C, Pepe J, Minisola S, Cipri C, Vescini F, Scillitani A et al. Clinical presentation and management of patients with primary hyperparathyroidism in Italy. Journal of Endocrinological Investigation 201841 1339-1348. (https://doi.org/10.1007/s40618-018-0879-z)

148 Mihai R, Barczynski M, Iacobone M \& Sitges-Serra A. Surgical strategy for sporadic primary hyperparathyroidism an evidence-based approach to surgical strategy, patient selection, surgical access, and reoperations. Langenbeck's Archives of Surgery 2009394 785-798. (https://doi.org/10.1007/s00423-009-0529-1)

149 Zini M, Attanasio R, Cesareo R, Emmolo I, Frasoldati A, Gianotti L, Guglielmi R, Piovesan A, Procopio M, Scillitani A et al. AME position statement: primary hyperparathyroidism in clinical practice. Journal of Endocrinological Investigation 201235 2-21. (https://doi. org/10.1007/BF03345413)
150 Marcocci C, Brandi ML, Scillitani A, Corbetta S, Faggiano A, Gianotti L, Migliaccio S \& Minisola S. Italian Society of Endocrinology Consensus Statement: definition, evaluation and management of patients with mild primary hyperparathyroidism. Journal of Endocrinological Investigation 201538 577-593. (https://doi. org/10.1007/s40618-015-0261-3)

151 Bollerslev J. The important players in primary hyperparathyroidism. Clinical Endocrinology 201379 774-775. (https://doi.org/10.1111/ cen.12291)

152 Lorente-Poch L, Sancho JJ, Ruiz S \& Sitges-Serra A. Importance of in situ preservation of parathyroid glands during total thyroidectomy. British Journal of Surgery 2015102 359-367. (https://doi.org/10.1002/ bjs.9676)

153 Hadker N, Egan J, Sanders J, Lagast H \& Clarke BL. Understanding the burden of illness associated with hypoparathyroidism reported among patients in the PARADOX study. Endocrine Practice 201420 671-679. (https://doi.org/10.4158/EP13328.OR)

154 Lopes MP, Kliemann BS, Bini IB, Kulchetscki R, Borsani V, Savi L, Borba VZ \& Moreira CA. Hypoparathyroidism and pseudohypoparathyroidism: etiology, laboratory features andcomplications. Archives of Endocrinology and Metabolism $2016 \mathbf{6 0}$ 532-536. (https:// doi.org/10.1590/2359-3997000000221)

155 Winer KK, Ko CW, Reynolds JC, Dowdy K, Keil M, Peterson D, Gerber LH, McGarvey C \& Cutler GB, Jr. Long-term treatment of hypoparathyroidism: a randomized controlled study comparingparathyroid hormone-(1-34) versus calcitriol and calcium. Journal of Clinical Endocrinology \& Metabolism 200388 4214-4220. (https://doi.org/10.1210/jc.2002-021736)

Received 27 April 2019

Revised version received 3 June 2019

Accepted 7 June 2019 